\title{
Deregulation of calcium homeostasis mediates secreted $\alpha$-synuclein-induced neurotoxicity
}

\author{
Katerina Melachroinou ${ }^{a}$, Maria Xilouri ${ }^{a}$, Evangelia Emmanouilidou ${ }^{a}$, Roser Masgrau ${ }^{\text {b }}$, \\ Panagiota Papazafiri ${ }^{c}$, Leonidas Stefanis ${ }^{\text {a,d }}{ }^{\text {, Kostas Vekrellis }}{ }^{\mathrm{a}, *}$ \\ ${ }^{a}$ Division of Basic Neurosciences, Biomedical Research Foundation of the Academy of Athens, Athens, Greece \\ ${ }^{\mathrm{b}}$ Department de Bioquímica i Biologia Molecular, and Institut de Neurociències, Universitat Autònoma de Barcelona, Barcelona, Catalonia, Spain \\ ${ }^{\mathrm{c}}$ Division of Animal and Human Physiology, Department of Biology, University of Athens, Athens, Greece \\ ${ }^{\mathrm{d}}$ Second Department of Neurology, University of Athens Medical School, Athens, Greece
}

\section{A R T I C L E I N F O}

Article history:

Received 22 January 2013

Received in revised form 4 June 2013

Accepted 14 June 2013

\section{Keywords:}

Parkinson's disease

Alpha-synuclein

Secretion

Exosomes

Calpains

Membrane fluidity

Mitochondria

Neurodegeneration

\begin{abstract}
A B S T R A C T
$\alpha$-Synuclein (AS) plays a crucial role in Parkinson's disease pathogenesis. AS is normally secreted from neuronal cells and can thus exert paracrine effects. We have previously demonstrated that naturally secreted AS species, derived from SH-SY5Y cells inducibly overexpressing human wild type AS, can be toxic to recipient neuronal cells. In the current study, we show that application of secreted AS alters membrane fluidity and increases calcium $\left(\mathrm{Ca}^{2+}\right)$ entry. This influx is reduced on pharmacological inhibition of voltage-operated $\mathrm{Ca}^{2+}$ channels. Although no change in free cytosolic $\mathrm{Ca}^{2+}$ levels is observed, a significantly increased mitochondrial $\mathrm{Ca}^{2+}$ sequestration is found in recipient cells. Application of voltage-operated $\mathrm{Ca}^{2+}$ channel blockers or $\mathrm{Ca}^{2+}$ chelators abolishes AS-mediated toxicity. AS-treated cells exhibit increased calpain activation, and calpain inhibition greatly alleviates the observed toxicity. Collectively, our data suggest that secreted AS exerts toxicity through engagement, at least in part, of the $\mathrm{Ca}^{2+}$ homeostatic machinery. Therefore, manipulating $\mathrm{Ca}^{2+}$ signaling pathways might represent a potential therapeutic strategy for Parkinson's disease.
\end{abstract}

(c) 2013 Elsevier Inc. All rights reserved.

\section{Introduction}

The pathological hallmark of Parkinson's disease (PD) is the loss of the dopaminergic neurons primarily in the substantia nigra pars compacta and the presence of proteinaceous inclusions, termed Lewy bodies and Lewy neutites, in the somata or axons, respectively, of the remaining neurons (Dauer and Przedborski, 2003; Spillantini et al., 1997). The primary structural component of these intraneuronal aggregates is $\alpha$-synuclein (AS), a small acidic protein that is mainly found in presynaptic terminals. AS is genetically linked to familial and sporadic disease (Gasser, 2009; Nalls et al., 2011). Importantly, AS is detected in human biological fluids and in the culture medium of neuronal cells, suggesting a possible paracrine mode of action in the extracellular milieu (Vekrellis et al., 2011). AS has been found to be secreted, via a nonclassical, calcium-dependent mechanism that partly relies on exosomes (Emmanouilidou et al., 2010), small extracellular vesicles

\footnotetext{
* Corresponding author at: Division of Basic Neurosciences, Biomedical Research Foundation of the Academy of Athens (BRFAA), 4, Soranou Efessiou Street, Athens 11527, Greece. Tel.: +30 210 6597523; fax: +30 2106597545

E-mail address: vekrellis@bioacademy.gr (K. Vekrellis).
}

which derive from endosomes after fusing with the plasma membrane (Chivet et al., 2012). Extracellular AS can be toxic to recipient cells, and has assumed an augmented importance, for the reason that it might be involved in disease propagation, otherwise known as 'spreading' in the context of PD (Kordower et al., 2008; Li et al., 2008).

It has been shown that aberrant forms of recombinant AS (oligomers, aggregates) can create pores that compromise plasma membrane integrity, much like other aggregating-prone proteins such as amyloid beta peptide and prion (Danzer et al., 2007; Tsigelny et al., 2012). Alternatively, such proteins can interact with calcium $\left(\mathrm{Ca}^{2+}\right)$ channels, thereby altering their function and compromising $\mathrm{Ca}^{2+}$ equilibrium between intracellular and extracellular spaces (Demuro et al., 2010). $\mathrm{Ca}^{2+}$ ions play a pivotal role in neuronal plasticity and survival (Berridge et al., 2003; Greer and Greenberg, 2008); thus, an extremely complex homeostatic network operates to regulate intracellular $\mathrm{Ca}^{2+}$ levels. $\mathrm{Ca}^{2+}$ influx has long been considered as a key source of $\mathrm{Ca}^{2+}$ signals, and together with $\mathrm{Ca}^{2+}$ release from internal stores, such as the endoplasmic reticulum (ER), plays a major role in $\mathrm{Ca}^{2+}$ homeostasis (Patel and Docampo, 2010). Acidic organelles have also been shown to be intracellular $\mathrm{Ca}^{2+}$ stores (Churchill et al., 2002; Yamasaki et al., 2004) and 
emerging evidence highlights their important role in $\mathrm{Ca}^{2+}$ signaling and cell physiology (Patel and Docampo, 2010). Additionally, mitochondria play a very important role on $\mathrm{Ca}^{2+}$ signaling, being physically and functionally linked to the ER, thus shaping intracellular $\mathrm{Ca}^{2+}$ responses (de Brito and Scorrano, 2008; Lamarca and Scorrano, 2009).

Deregulation of $\mathrm{Ca}^{2+}$ homeostasis has been recently proposed as a major age-related condition driving neurodegeneration in sporadic PD (Zundorf and Reiser, 2011). This view is supported by the finding that dopaminergic neurons expressing higher levels of $\mathrm{Ca}^{2+}$-binding proteins, such as calbindin D28K, calretinin, and parvalbumin, seem to be resistant to degeneration in PD (Surmeier et al., 2010). Moreover, recombinant AS has been shown to trigger $\mathrm{Ca}^{2+}$ influx and induce caspase activation in a variety of neuronal systems (Danzer et al., 2007; Furukawa et al., 2006; Martin et al., 2012). However, the effects of cell-derived naturally secreted AS on $\mathrm{Ca}^{2+}$ homeostasis in a neuronal cell context have not been assessed.

To address this issue, we have used the human SH-SY5Y neuroblastoma cell line, in which the expression of human wild type (WT) AS can be induced, as a source of naturally secreted AS (Vekrellis et al., 2009). We have previously shown that these cells readily secrete a wide range of AS species, which are toxic to recipient neuronal cells (Emmanouilidou et al., 2010). Here, we show that application of medium enriched in secreted AS on neuronally differentiated SH-SY5Y cells and primary rat cortical neurons, is accompanied by perturbation of $\mathrm{Ca}^{2+}$ homeostasis and neuronal death. These effects are ameliorated by blockage of voltage-operated $\mathrm{Ca}^{2+}$ channels (VOCs), $\mathrm{Ca}^{2+}$ chelation, or calpain inhibition. The increase in $\mathrm{Ca}^{2+}$ influx is mostly attributed to free extracellular, rather than exosome-associated AS. We further show that extracellular AS alters membrane fluidity properties of the recipient cells, and evokes $\mathrm{Ca}^{2+}$ sequestration into the mitochondria. Collectively, our data suggest that secreted AS is toxic to recipient neuronal cells, at least in part, through the disruption of the $\mathrm{Ca}^{2+}$ homeostatic machinery.

\section{Methods}

\subsection{Reagents}

Reagents were obtained from Sigma-Aldrich (St Louis, MO, USA) unless otherwise specified. G agarose beads, Fluorogenic Substrate IV, and Fura 2-AM calcium indicator were purchased from Calbiochem (San Diego, CA, USA). Carbonyl cyanide p-trifluromethoxyphenylhydrazone (FCCP), $\omega$-conotoxin GVIA (cntx) and SKF 96365 hydrochloride (SKF) were purchased from Tocris Bioscience. 1-Pyrenedodecanoic acid was obtained from Molecular Probes/ Invitrogen (Eugene, OR, USA).

\subsection{Cell culture}

Stable SH-SY5Y cell lines inducibly expressing WT AS were generated as previously described (Vekrellis et al., 2009). Cells were cultured in RPMI 1640 medium containing 10\% fetal bovine serum (FBS), penicillin (100 U/mL), streptomycin $(100 \mu \mathrm{g} / \mathrm{mL})$, and $2 \mathrm{mM}$ L-glutamine. AS expression was switched off by the addition of doxycycline (dox) $(1.0 \mu \mathrm{g} / \mathrm{mL})$. Neuronal differentiation was performed with the addition of $10 \mu \mathrm{M}$ all-trans retinoic acid for 6 days. Cultures of rat (embryonic day 18) cortical neurons were prepared as previously described (Vogiatzi et al., 2008). Dissociated cells were plated onto poly-D-lysine-coated 24-well dishes at a density of 150,000-200,000 cells per $\mathrm{cm}^{2}$ and maintained in Neurobasal medium (Gibco, Invitrogen), containing 2\% B27 supplement (Gibco, Invitrogen), $0.5 \mathrm{mM}$ L-glutamine, and 1\% penicillin/streptomycin.

\subsection{Preparation of conditioned medium}

SH-SY5Y cells inducibly expressing WT AS were cultured in 140 mm dishes in RPMI medium containing 10\% FBS in the presence (1.0 $\mu \mathrm{g} / \mathrm{mL}$ ) or absence of dox until $70 \%-80 \%$ confluency was reached. The medium was then replaced with RPMI containing $2 \%$ FBS. After 48 hours, the culture supernatant (conditioned medium [CM]) was collected and centrifuged sequentially at $400 \mathrm{~g}$ for 5 minutes at $4{ }^{\circ} \mathrm{C}$ to remove unbroken cells and at $4000 \mathrm{~g}$ for 10 minutes at $4{ }^{\circ} \mathrm{C}$ to remove cell debris.

\subsection{Exosome purification}

Before use, FBS exosomes were depleted from the culture medium as described previously (Thery et al., 2006). Before exosome isolation, the culture medium of SH-SY5Y cells was replaced with exosome-depleted medium diluted 10-fold with RPMI containing only penicillin/streptomycin and L-glutamine for 48 hours. The culture supernatant was collected and sequentially centrifuged at $400 \mathrm{~g}$ for 10 minutes, and at $2000 \mathrm{~g}$ for 10 minutes, $10,000 \mathrm{~g}$ for 30 minutes, and $100,000 \mathrm{~g}$ for 90 minutes. The obtained pellet (P100) containing mostly exosomes was washed once with icecold phosphate buffered saline (PBS) and centrifuged again at $100,000 \mathrm{~g}$ for 90 minutes. The final P100 pellet was resuspended in PBS buffer or lysed in radioimmunoprecipitation assay (RIPA) buffer.

\subsection{Immunodepletion of AS from CM}

AS was immunodepleted from $\mathrm{CM}$ as described previously (Emmanouilidou et al., 2010). The anti-AS antibody (Syn-1, mouse monoclonal; BD Biosciences; $0.5 \mu \mathrm{g}$ antibody per $\mathrm{mL} \mathrm{CM}$ ) was used to immunoprecipitate AS from the $\mathrm{CM}$ overnight. Immunodepleted $\mathrm{CM}$ was collected and sterilized through a $0.2 \mu \mathrm{m}$ filter (Whatman) before application to recipient cells. Control immunodepletion was performed using an anti-c-myc antibody of the same isotype (mouse monoclonal; Santa Cruz Biotechnology).

\subsection{Western blot analysis}

For Western blot analysis, CM and exosome-depleted supernatants (S100) were concentrated using 3-kDa cutoff Amicon Ultra filters (Millipore). The P100 containing exosomes was reconstituted in $25 \mu \mathrm{L}$ of RIPA buffer ( $50 \mathrm{mM}$ Tris- $\mathrm{HCl}, \mathrm{pH} \mathrm{7.6,150} \mathrm{mM} \mathrm{NaCl}, 1 \%$ NP-40, 0.5\% Na deoxycholate, and $0.1 \%$ sodium dodecyl sulfate). Denaturing gel electrophoresis was performed in $12 \%$ sodium dodecyl sulfate polyacrylamide gel electrophoresis gels in Trisglycine buffer. Immunoblot analysis was performed using the following antibodies: anti-AS (rabbit polyclonal; C-20), anti-bovine serum albumin (anti-BSA) (mouse monoclonal), anti-Alix (mouse monoclonal), and anti-Flotillin (mouse monoclonal). All antibodies were from Santa Cruz Biotechnology.

\subsection{Assessment of survival}

Six-day differentiated SH-SY5Y neuroblastoma cells or 7-dayold rat cortical neurons were treated with AS-containing (CM, WT-) or control (CM, WT+) CM in the presence or absence of $\mathrm{Ca}^{2+}$ modulators or calpain inhibitors. Concentrations of the compounds are mentioned in the figures. Recipient cells were lysed in a detergent-containing solution, which enables the quantification of viable cells by counting the number of intact nuclei in a hematocytometer (Farinelli et al., 1998; Stefanis et al., 1999). Cell counts were performed in triplicate. 


\subsection{In vitro assessment of calpain enzymatic activity}

Six-day differentiated SH-SY5Y human neuroblastoma cells, grown in 6-well plates, were incubated with control $\mathrm{CM}$ or $\mathrm{CM}$ containing secreted AS for 8, 12, 16, and 24 hours. Recipient cells were washed with ice-cold PBS and homogenized in a buffer containing 10 mM HEPES (pH 7.5), 5 mM DTT, 1\% NP-40 on ice for 30 minutes. Cell lysates $(2 \mu \mathrm{g})$ were mixed with $25 \mu \mathrm{L}$ of activity buffer (50 mM Tris-HCl [pH 7.6], $150 \mathrm{mM} \mathrm{NaCl}, 5 \mathrm{mM}$ DTT, $10 \mathrm{mM} \mathrm{CaCl}$ ) containing $10 \mu \mathrm{M}$ fluorogenic calpain substrate (Calpain Substrate IV; Calbiochem, San Diego, CA, USA) and incubated at room temperature for 40 minutes in the dark. The reaction was stopped by adding $500 \mu \mathrm{L}$ of $50 \mathrm{mM}$ EDTA. Calpain activity was measured at $320 \mathrm{~nm}$ after excitation at $480 \mathrm{~nm}$ in a Perkin-Elmer LS-55 luminescence spectometer (Perkin-Elmer, Norwalk, CT, USA). To test the specificity of the assay, $200 \mu \mathrm{M}$ of the calpain inhibitor I A6185 (CI) was included where indicated (Banoczi et al., 2008).

\subsection{1-Pyrenedodecanoic acid fluorescence measurements}

1-Pyrenedodecanoic acid labeling of plasma membranes and fluorescence measurements were carried out as described elsewhere (Galla and Luisetti, 1980; Hashimoto et al., 1999). SH-SY5Y cells were seeded on 6 -well plates at a density of $1.0 \times 10^{5}$ cells per well, and differentiated for 6 days. Subsequently, cells were treated with secreted CM, WT- for 8 hours at $37^{\circ} \mathrm{C}$. At the end of the incubation period, cells were resuspended in PBS and transferred into a fluorimeter cuvette. 1-Pyrenedodecanoic acid $(2 \mu \mathrm{M})$ was added for 5 minutes in the dark at room temperature (RT). After excitation at $340 \mathrm{~nm}$, the fluorescence intensity was scanned from 380 to $580 \mathrm{~nm}$ in a luminescence spectrometer. The ratio of the maximum fluorescent intensity of excimer and pyrene monomers was calculated at 468 and $395 \mathrm{~nm}$, respectively.

\subsection{Free cytosolic $\mathrm{Ca}^{2+}$ measurements}

Cells were loaded with Fura 2-AM as described (Papazafiri et al., 1994). Briefly, 6-day differentiated SH-SY5Y cells were treated with control or secreted CM, WT - for 8 hours, harvested in RPMI culture medium and centrifuged at $400 \mathrm{~g}$ for 5 minutes at RT. Cell pellets were suspended in Krebs-Ringer-HEPES (KRH) buffer $(125 \mathrm{mM}$ $\mathrm{NaCl}, 5 \mathrm{mM} \mathrm{KCl}, 1.2 \mathrm{mM} \mathrm{KH}_{2} \mathrm{PO}_{4}, 1.2 \mathrm{mM} \mathrm{MgSO}_{4}, 2 \mathrm{mM} \mathrm{CaCl}_{2}, 6 \mathrm{mM}$ D-glucose, and $25 \mathrm{mM}$ HEPES-NaOH [pH 7.4]) containing 2\% FBS, counted in a hemocytometer and loaded with Fura 2-AM dye (2.5 $\mu \mathrm{M})$, for 30 minutes at RT in the dark. Cells were resuspendend in KRH supplemented with $250 \mathrm{mM}$ sulfinpyrazone to prevent dye leakage, transferred to a thermostatted cuvette $\left(37^{\circ} \mathrm{C}\right)$, maintained in a continuous stirring condition, and analyzed in a Perkin-Elmer LS-55 luminescence spectrometer. To estimate capacitative calcium entry (CCE), $1.8 \times 10^{6}$ cells were resuspended in a $\mathrm{CaCl}_{2^{-}}$ deprived KRH medium and $10 \mu \mathrm{M}$ EGTA was added. Thapsigargin ([Tg] $100 \mathrm{nM}$ ) was added to deplete ER $\mathrm{Ca}^{2+}$ stores; $\mathrm{CaCl}_{2}(3 \mathrm{mM})$ was reintroduced into the medium and the ensuing CCE was recorded. Results represent the maximal peak values normalized to ER content as exemplified by $\mathrm{Tg}$-induced $\mathrm{Ca}^{2+}$ efflux of at least 3 independent experiments. Nifedipine ([nif] $1 \mu \mathrm{M})$, cntx (100 nM), or SKF $(10 \mu \mathrm{M})$ was added after EGTA normalization and before the addition of $\mathrm{Tg}$. VOCs were stimulated with $55 \mathrm{mM} \mathrm{KCl}$, in the presence or absence of either $1 \mu \mathrm{M}$ nif or $100 \mathrm{nM}$ cntx. To estimate $\mathrm{Ca}^{2+}$ load in the diverse subcellular compartments, intracellular $\mathrm{Ca}^{2+}$ pools were depleted sequentially with the addition of the appropriate pharmacological compounds: $5 \mu \mathrm{M}$ carbachole (Cch), followed by the addition of $100 \mathrm{nM} \mathrm{Tg}, 500 \mathrm{nM}$ ionomycin (Iono), and $20 \mu \mathrm{M}$ monensin $\mathrm{A}$, in the presence or absence of extracellular $\mathrm{Ca}^{2+}$. To estimate the mitochondrial $\mathrm{Ca}^{2+}$ load, $1.8 \times 10^{6}$ Fura 2-loaded cells suspended in $\mathrm{Ca}^{2+}$-deprived $\mathrm{KRH}$, were treated with $5 \mu \mathrm{M}$ of the mitochondrial uncoupler FCCP, together with $2.5 \mu \mathrm{g} / \mathrm{mL}$ oligomycin (Oligo), to prevent ATP consumption via the reversed mode activity of the F1/F0 synthase.

\subsection{Live $\mathrm{Ca}^{2+}$ imaging}

For live $\mathrm{Ca}^{2+}$ imaging, 7-day-old rat cortical neurons (75,000 cells per chamber) plated on poly-L-lysine-coated 8-chamber slides (Integrated BioDiagnostics, Munich, Germany), were incubated with 2 $\mu \mathrm{M}$ Fura 2-AM in culture medium for 30 minutes at $37{ }^{\circ} \mathrm{C}$, then returned to culture medium and incubated for 3 hours at $37^{\circ} \mathrm{C}$. Just before $\mathrm{Ca}^{2+}$ measurements, cells were washed once with microscopy buffer $(129 \mathrm{mM} \mathrm{NaCl}, 5 \mathrm{mM} \mathrm{KCl}, 1 \mathrm{mM} \mathrm{MgCl}$, $30 \mathrm{mM}$ glucose, $1 \% \mathrm{BSA}$, $25 \mathrm{mM}$ HEPES [pH 7.4]) and positioned in a temperature-controlled microscope. During measurements, CCE was assessed using stimulation with $0.25 \mu \mathrm{M} \mathrm{Tg}$, followed by the addition of $6 \mathrm{mM} \mathrm{CaCl}_{2}$. Fluorescence images obtained at 340 and $380 \mathrm{~nm}$ excitation and 510 $\mathrm{nm}$ emission were acquired by using a TE 2000U-inverted fluorescence microscope (Nikon, Osaka, Japan) coupled to a cooled chargecoupled device (CCD) camera (PTI-IC200) (Princeton Instruments). At the end of each experiment, the Fura 2-AM signals were calibrated with the simultaneous addition of $10 \mu \mathrm{M}$ Iono and $50 \mathrm{mM} \mathrm{KCl}$, to obtain the maximum fluorescence. Images were acquired every 10 seconds and cells were analyzed using the region of interest tool, to extract the fluorescence ratios. Changes in $\mathrm{Ca}^{2+}$ were determined using temporal analyses of single cells to express the data as fluorescence ratios as described (Smaili and Russell, 1999). The baseline fluorescence was determined at the beginning of each experiment by obtaining the average of the first 20 data points before compound addition, using the Image Master 3 Software (Graph-Pad Prism 4.0) acquisition-analysis software (PTI, Birmingham, NJ, USA). The results were normalized in relation to the baseline fluorescence and the data expressed as a percent of increase relative to baseline. The histograms represent the average peak response.

\subsection{Statistical analysis}

All data are expressed as mean \pm standard error of the mean (SEM). Statistical analysis for multiple comparisons was performed using a 1-way analysis of variance followed by Tukey honestly significant difference (HSD) post hoc test. Nondirectional Student $t$ tests were performed for comparisons involving only 2 groups. All statistical analyses were conducted using the Graph-Pad Prism software. Results were considered statistically significant at $p \leq 0.05$.

\section{Results}

\subsection{Secreted AS induces an increase in capacitative $\mathrm{Ca}^{2+}$ entry in neuronally differentiated SH-SY5Y neuroblastoma cells}

We wanted to investigate whether the mechanism via which secreted AS triggers the neurotoxic cascade involves alterations in the $\mathrm{Ca}^{2+}$ homeostastic machinery. As a source of cell-secreted AS, we used CM from SH-SY5Y cells inducibly overexpressing human WT AS (Emmanouilidou et al., 2010; Vekrellis et al., 2009). To elucidate the events that precede AS-induced cell death, we applied $\mathrm{CM}$ from the induced (CM, WT-) or the control uninduced cells $(\mathrm{CM}, \mathrm{WT}+)$ to differentiated SH-SY5Y cells for 8 hours, because this was the longest incubation time during which the recipient cells did not exhibit any morphological or biochemical characteristics of cell degeneration (data not shown). After the 8hour treatment, free cytosolic $\mathrm{Ca}^{2+}\left(\left[\mathrm{Ca}^{2+}\right]_{i}\right)$ recordings of the recipient cells were obtained using the Fura 2-AM dye. After ER depletion by $\mathrm{Tg}(100 \mathrm{nM})$, we measured CCE using exogenous 


\section{Differentiated SH-SY5Y cells}

A

CM, WT+

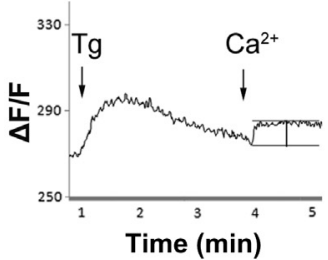

B CM, WT-/Syn-1 IP

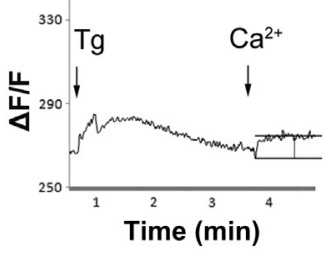

C

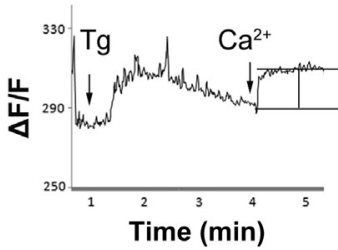

CM, WT-

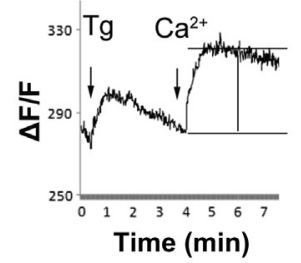

CM, WT-/c-myc IP

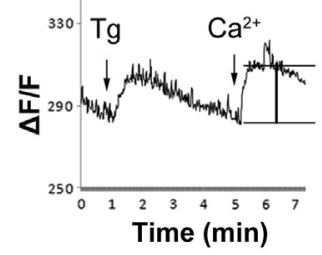

Normalized to $\mathrm{Tg}$

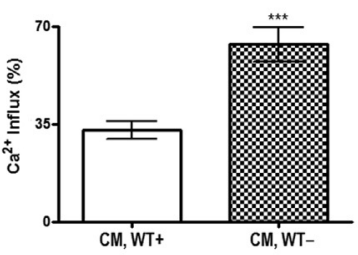

Normalized to $\mathrm{Tg}$

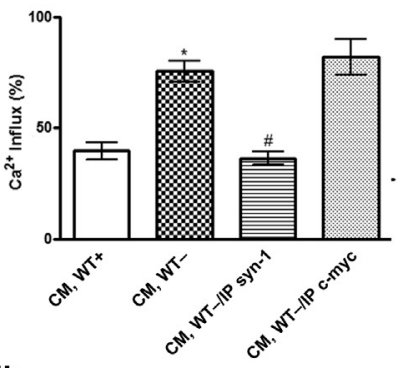

Proliferating SH-SY5Y cells CM, WT-

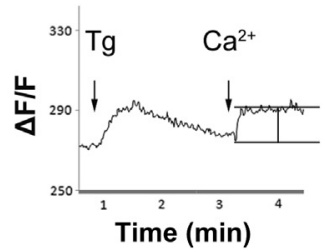

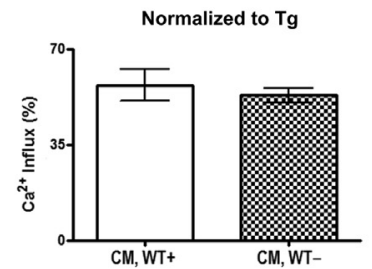

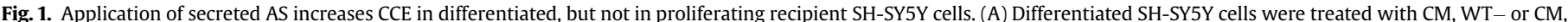

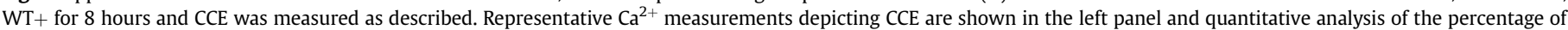

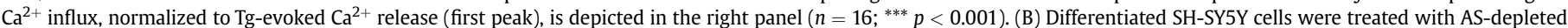

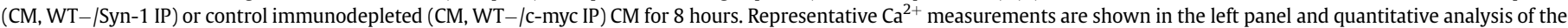

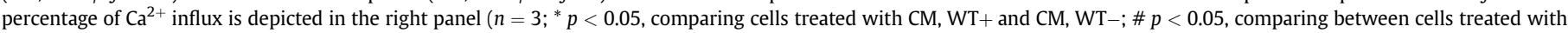

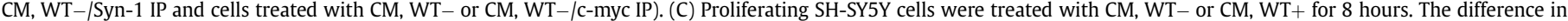

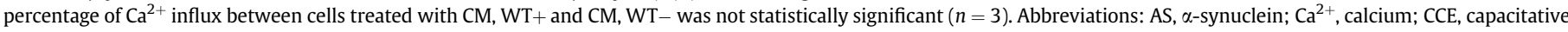

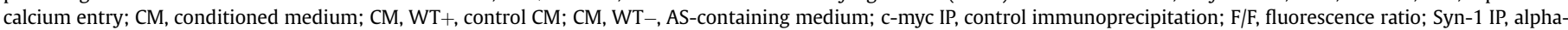
synuclein immunoprecipitation; $\mathrm{Tg}$, thapsigargin.

addition of $3 \mathrm{mM} \mathrm{CaCl}_{2}$ (Fig. 1). Treatment of differentiated SHSY5Y cells with the secreted CM, WT - resulted in a statistically significant increase in $\left[\mathrm{Ca}^{2+}\right]_{\mathrm{i}}$, compared with cultures incubated with CM, WT+ (Fig. 1A). Importantly, this increase in CCE was ASdependent, because effective immunodepletion of AS from the $\mathrm{CM}$, before its application to recipient cells, greatly reduced the $\mathrm{Tg}$ evoked $\mathrm{Ca}^{2+}$ entry (Fig. 1B). Control immunodepletion with an irrelevant antibody (c-myc) failed to reduce CCE. In contrast, incubation of proliferating SH-SY5Y cells with the CM, WT+ or the $\mathrm{CM}, \mathrm{WT}-$ resulted in similar CCE responses (Fig. 1C), suggesting that secreted AS only disturbs $\mathrm{Ca}^{2+}$ homeostasis in cells that have a neuronal phenotype.

\subsection{Secreted AS-induced increase in $\mathrm{Ca}^{2+}$ entry is amplified by the} $L$ - and the $\mathrm{N}$-type voltage-operated $\mathrm{Ca}^{2+}$ channels

In neurons, as in many other cell types, $\mathrm{Ca}^{2+}$ ions can enter cells via a number of channels, such as storage-operated channels (SOCs), VOCs, and receptor-operated plasma membrane $\mathrm{Ca}^{2+}$ channels. To assess the contribution of such channels to the ASfacilitated $\mathrm{Ca}^{2+}$ entry, we first examined the participation of SOCs by blocking them with the SOC-specific inhibitor, SKF $(10 \mu \mathrm{M})$. Addition of SKF resulted in a significant reduction in CCE, in secreted AS- and control CM-treated cultures (Fig. 2A and B). However, the difference in CCE between the 2 groups in the presence of SKF, was maintained (Fig. 2B), implying that other plasma membrane channels might participate in the observed $\mathrm{Ca}^{2+}$ entry in the presence of secreted AS.

Previous reports have suggested that AS modulates the function of VOCs (Adamczyk and Strosznajder, 2006; Hettiarachchi et al., 2009; Kang et al., 2012). To test such a hypothesis in our cellular system, we used the L- and N-type specific VOC blockers, nif $(1 \mu \mathrm{M})$ and cntx (100 nM), respectively. We found that nif and cntx reduced the Tg-evoked $\mathrm{Ca}^{2+}$ entry, only in cells treated with secreted AS (Fig. 2C and D). These results imply a participation of both $\mathrm{L}-$ and $\mathrm{N}$ type $\mathrm{Ca}^{2+}$ channels in the observed CCE increase. Neither inhibitor affected the CCE of cells treated with the CM, WT+. Based on these findings we could surmise that in the presence of extracellular AS, VOCs might become active, thereby contributing to the SOCfacilitated $\mathrm{Ca}^{2+}$ entry.

To directly investigate the role of VOCs, we stimulated the cells with $55 \mathrm{mM} \mathrm{KCl}$. Control and AS-treated cells responded to $\mathrm{KCl}$ stimulation robustly, yet $\mathrm{Ca}^{2+}$ entry was significantly greater in the latter (Fig. 2E and F). Addition of either nif or cntx, significantly reduced $\mathrm{KCl}$-induced $\mathrm{Ca}^{2+}$ entry in both groups, verifying the functionality of these channels. Notably, the 


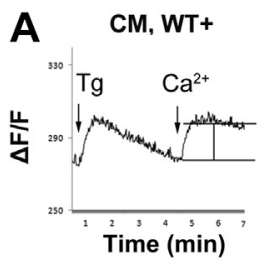

CM, WT-

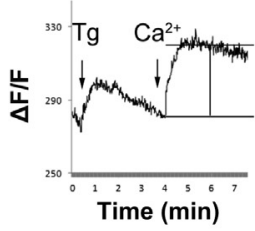

C $\mathrm{CM}, \mathrm{WT}+/ 1 \mu \mathrm{M}$ nif

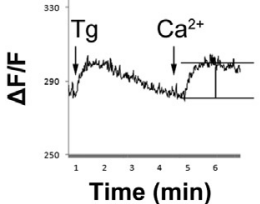

CM, WT-I1 $\mu \mathrm{M}$ nif
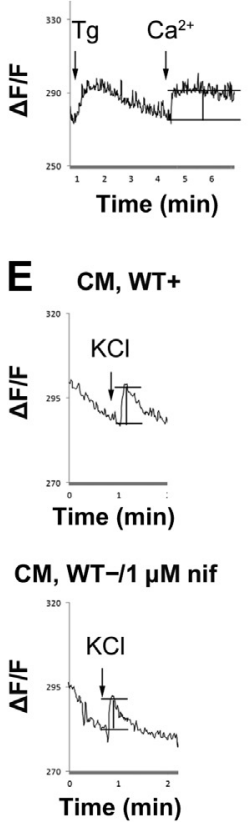

$\mathrm{CM}, \mathrm{WT}+110 \mu \mathrm{M}$ SKF

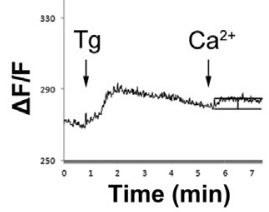

CM, WT-I10 $\mu \mathrm{M}$ SKF

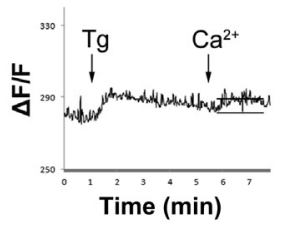

CM, WT+/100 nM cntx

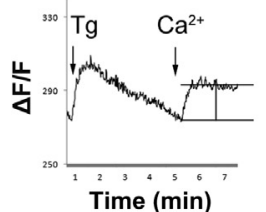

CM, WT-I100 nM cntx

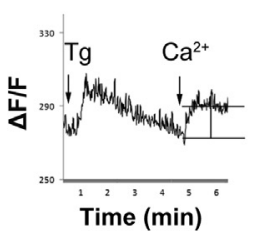

CM, WT-

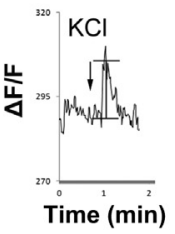

$\mathbf{F}$

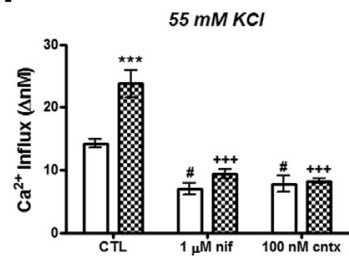

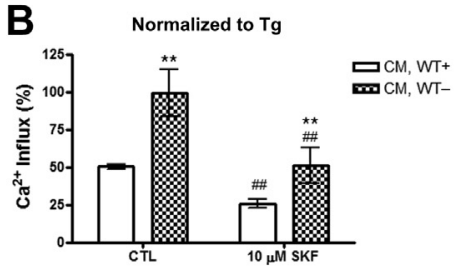

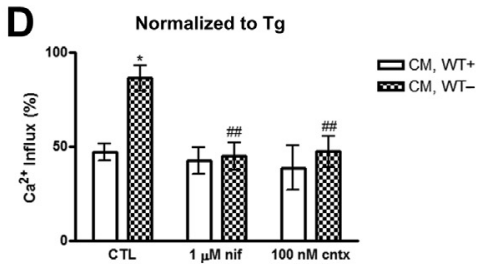

CM, WT-/100 nM cntx

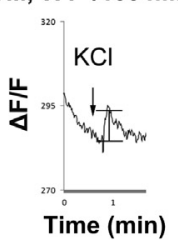

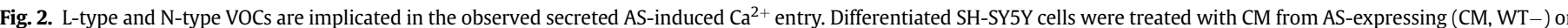

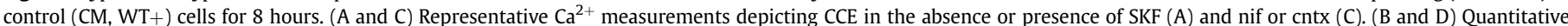

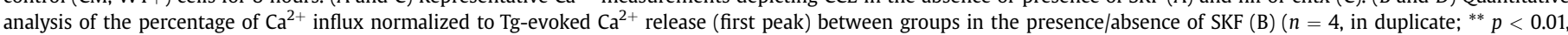

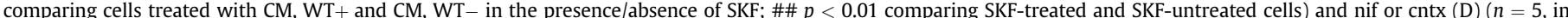

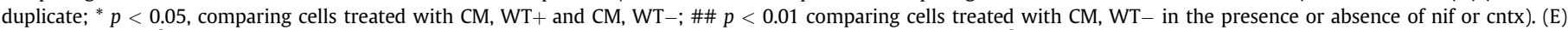

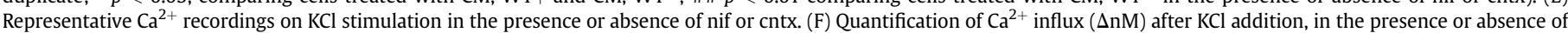

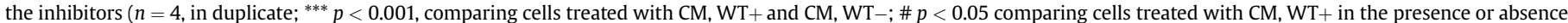

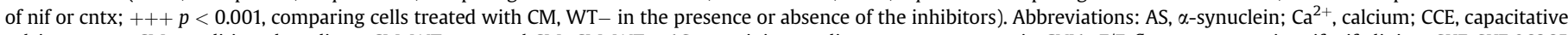

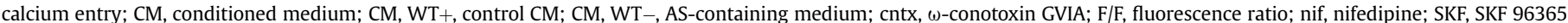
hydrochloride; $\mathrm{Tg}$, thapsigargin; VOC, voltage-operated $\mathrm{Ca}^{2+}$ channel.

difference in $\mathrm{Ca}^{2+}$ influx between control and AS-treated cells was abolished in the presence of VOC inhibitors (Fig. 2F), highlighting the important role of these channels in secreted ASfacilitated $\mathrm{Ca}^{2+}$ entry.

\subsection{Naturally secreted AS induces mitochondrial $\mathrm{Ca}^{2+}$ uptake}

Increased intracellular AS, and prefibrilar forms of recombinant AS, have been shown to induce higher plasma membrane ion 
A

Cytosolic

$\mathrm{Ca}^{2+}$-deprived medium

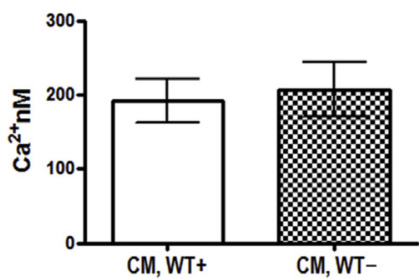

$\mathrm{Ca}^{2+}$-containing medium

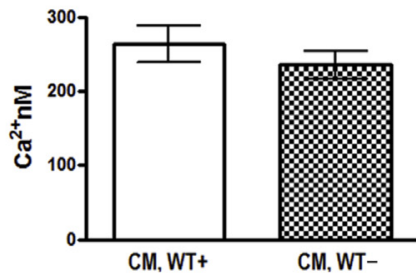

B

$\mathrm{Ca}^{2+}$-Deprived conditions

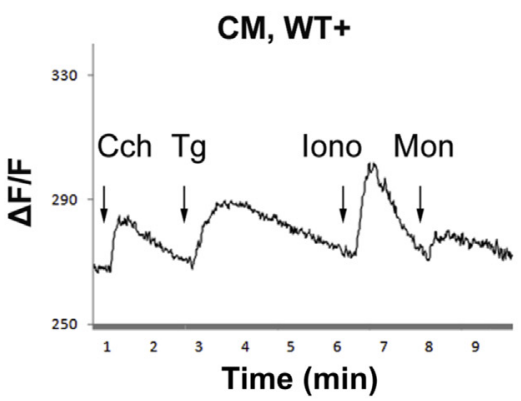

CM, WT-
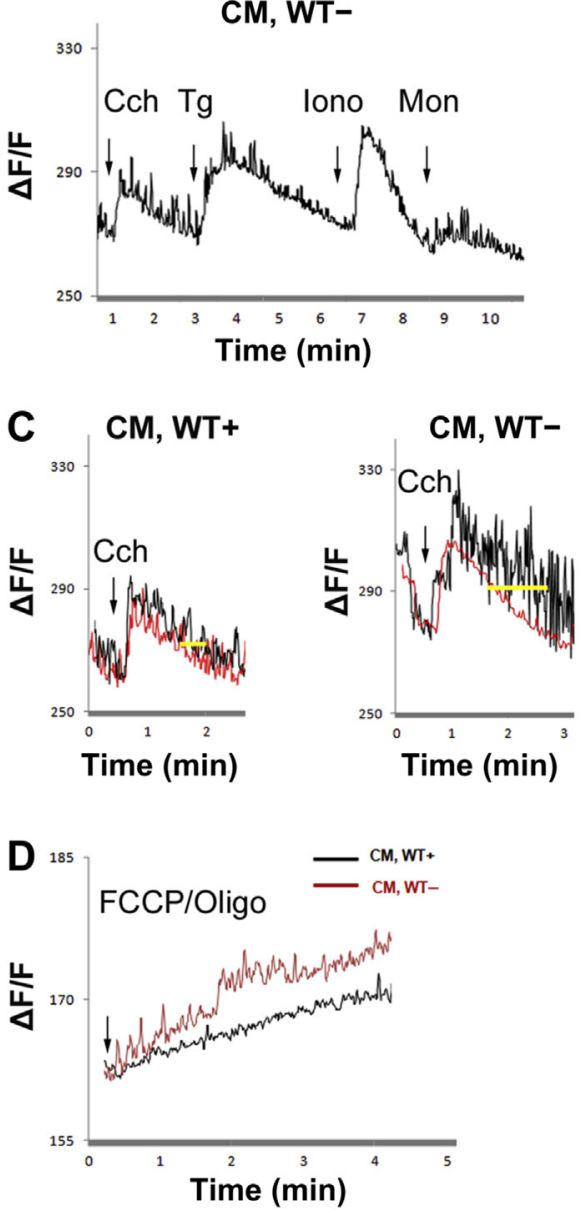

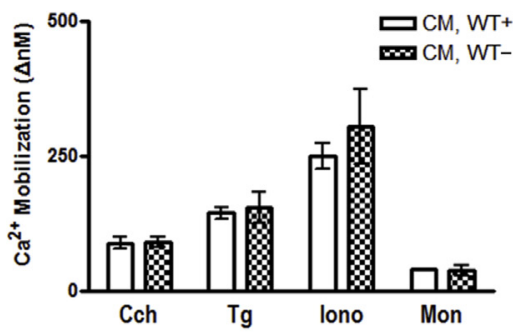

Latency to Cch response
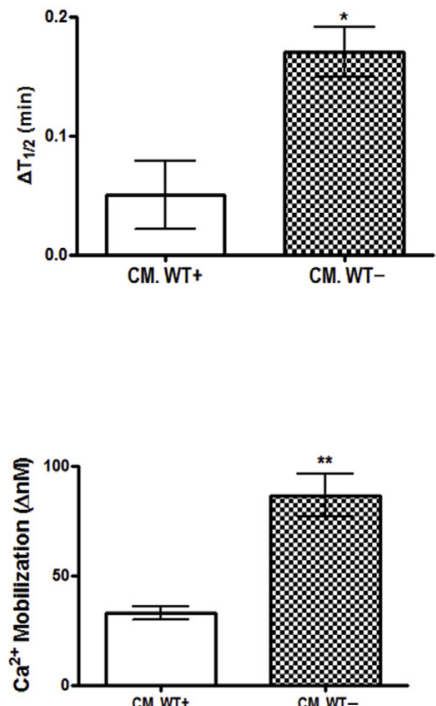

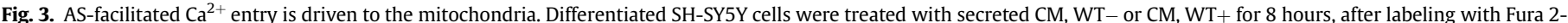

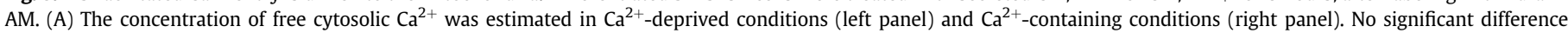

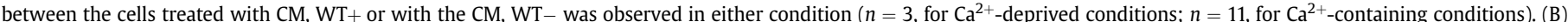

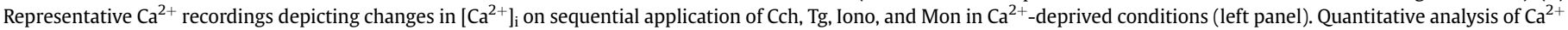

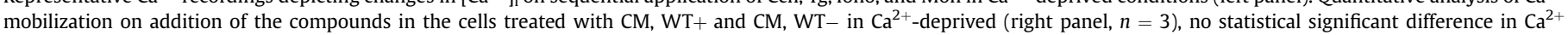


Rat cortical neurons
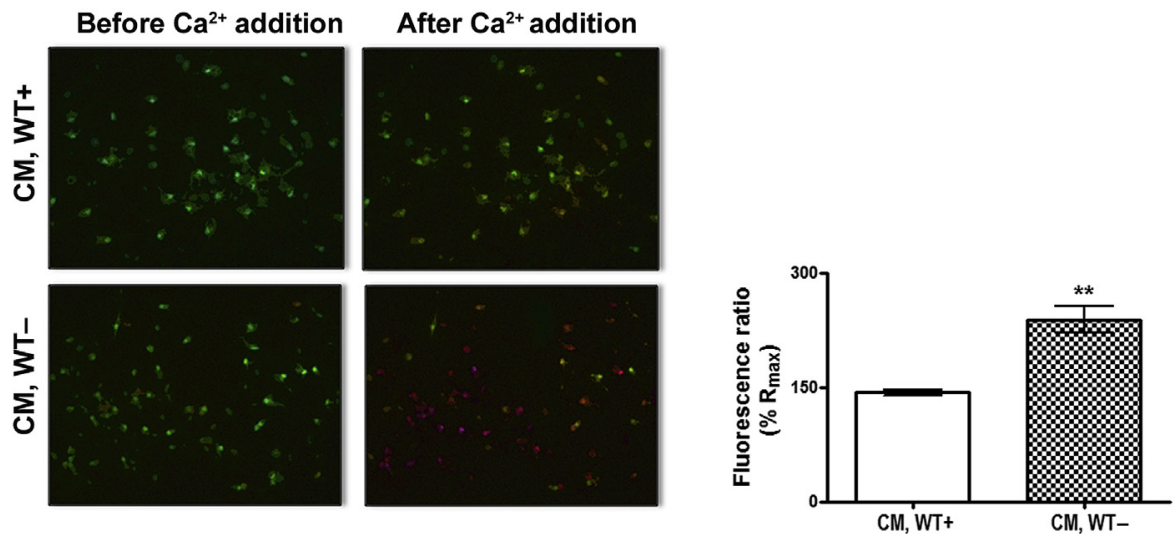

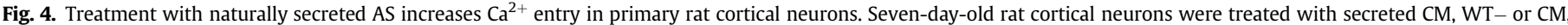

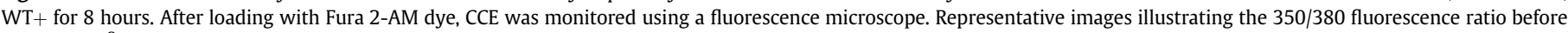

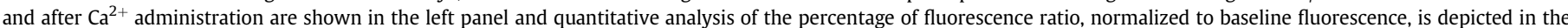

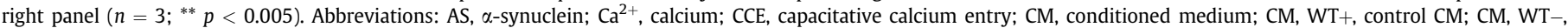
AS-containing medium; $\% \mathrm{R}_{\max }$, percent of increase relative to baseline.

permeability and subsequent $\left[\mathrm{Ca}^{2+}\right]_{i}$ rise (Danzer et al., 2007; Furukawa et al., 2006). Taking these, and our results, into account, we investigated whether the increased $\mathrm{Ca}^{2+}$ entry could lead to a subsequent rise in $\left[\mathrm{Ca}^{2+}\right]_{i}$ levels. To this end, differentiated SH-SY5Y cells were treated as previously described and $\left[\mathrm{Ca}^{2+}\right]_{i}$ levels were examined in $\mathrm{Ca}^{2+}$-free and $\mathrm{Ca}^{2+}$-containing environments. No significant difference in $\left[\mathrm{Ca}^{2+}\right]_{i}$ was observed between AS-treated and control-treated cells in either condition (Fig. 3A).

Next, we asked whether the increased $\mathrm{Ca}^{2+}$ entry could lead to sequestration into specific intracellular $\mathrm{Ca}^{2+}$ pools. Under $\mathrm{Ca}^{2+}$ deprived conditions, we first added $\operatorname{Cch}(5 \mu \mathrm{M})$, a cholinergic agonist that activates inositol trisphosphate receptor $\left(\mathrm{IP}_{3} \mathrm{R}\right)$, resulting in $\mathrm{Ca}^{2+}$ efflux from the ER to the cytosol. When the Cch response was buffered, Tg (100 nM), a noncompetitive inhibitor of sarcoendoplasmic reticulum (SR) calcium transport ATPase (SERCA) pumps, was added to allow total ER $\mathrm{Ca}^{2+}$ depletion. Subsequently, we administered $500 \mathrm{nM}$ Iono, $\mathrm{a} \mathrm{Ca}^{2+}$ ionophore. After the Iono-evoked response, $20 \mu \mathrm{M}$ of the sodium ionophore $\left(\mathrm{Na}^{+} / \mathrm{H}^{+}\right.$exchanger), monensin $\mathrm{A}$, was added to release $\mathrm{Ca}^{2+}$ from acidic compartments, such as lysosomes. A representative $\mathrm{Ca}^{2+}$ trace after sequential addition of the examined agents is shown in Fig. 3B. Quantification of $\mathrm{Ca}^{2+}$ mobilization (i.e., $\mathrm{Ca}^{2+}$ rise), after the administration of each drug, revealed no statistically significant differences between AStreated and control cells (Fig. 3C). Similar results were obtained in $\mathrm{Ca}^{2+}$-containing conditions (data not shown).

Additionally, to further support our data regarding AS-induced $\mathrm{Ca}^{2+}$ entry, we investigated Cch-induced $\mathrm{Ca}^{2+}$ mobilization kinetics in differentiated cells exposed to secreted CM, WT - and CM, $\mathrm{WT}+$. Interestingly, the rate of $\mathrm{Ca}^{2+}$ buffering after stimulation with Cch in $\mathrm{Ca}^{2+}$-containing compared with $\mathrm{Ca}^{2+}$-deprived conditions was significantly slower in AS-treated compared with control cells (Fig. 3D). Because Cch triggers $\mathrm{Ca}^{2+}$ influx from the extracellular space as a secondary effect, the observed latency further supports that $\mathrm{CM}, \mathrm{WT}-$ potentiates $\mathrm{Ca}^{2+}$ entry from the plasma membrane, not only after stimuli such as $\mathrm{Tg}$, but also on more physiological stimulations such as Cch.
Altogether, these results show a facilitated calcium entry in cells cultured with CM, WT-, with no apparent preferential $\mathrm{Ca}^{2+}$ distribution in a subcellular compartment. However, it is important to note that there was a higher Iono-evoked $\mathrm{Ca}^{2+}$ release in AS-treated compared with control cells, in $\mathrm{Ca}^{2+}$-deprived conditions (Fig. 3B, right panel). Although it did not reach statistical significance, this trend implies the participation of a different subcellular $\mathrm{Ca}^{2+}$ pool. Therefore, we examined whether the mitochondria could be a potential pool for $\mathrm{Ca}^{2+}$ sequestration. To this end, $5 \mu \mathrm{M}$ of the mitochondrial uncoupler, FCCP, together with $2.5 \mu \mathrm{g} / \mathrm{mL}$ Oligo were added to control and AS-treated cells. Oligo prevents ATP consumption via the reversed mode activity of the F1/F0 synthase. In $\mathrm{Ca}^{2+}$-deprived conditions, addition of FCCP with Oligo discharges mitochondrial $\mathrm{Ca}^{2+}$ stores, causing a rise of cytosolic $\left[\mathrm{Ca}^{2+}\right]_{\mathrm{i}}$, which reflects the mitochondrial $\mathrm{Ca}^{2+}$ load (Hettiarachchi et al., 2009). Secreted AS-treated cells exhibited a more profound response to the FCCP/Oligo treatment (Fig. 3E). Quantification of the $\mathrm{Ca}^{2+}$ mobilization on drug administration (expressed as $\Delta \mathrm{nM}\left[\mathrm{Ca}^{2+}\right]_{\mathrm{i}}$ at 4 minutes after drug addition) revealed significantly higher levels of mitochondrial $\mathrm{Ca}^{2+}$ content in AS-treated cells compared with control cells ( $32.83 \pm 2.97$ and $86.36 \pm 9.75$, comparing cells treated with CM, WT+ and CM, WT-, respectively) (Fig. 3E). These results suggest that on exposure of recipient cells to $\mathrm{CM}, \mathrm{WT}-$, part of the excessive $\mathrm{Ca}^{2+}$ entry is driven to the mitochondrial $\mathrm{Ca}^{2+}$ pool.

\subsection{Cell-secreted AS leads to a profound increase in CCE in primary rat cortical neurons}

We have previously shown that primary cortical neurons are also susceptible to secreted AS neurotoxic effects (Emmanouilidou et al., 2010). We further examined whether application of cellsecreted AS on primary rat cortical neurons had similar effects on $\mathrm{Ca}^{2+}$ influx. To this end, 7-day-old rat cortical neurons were treated with CM, WT - or CM, WT+ for 8 hours, after loading with Fura 2AM and changes in CCE were recorded. As shown in Fig. 4, cortical neurons receiving secreted AS exhibited a profound increase in

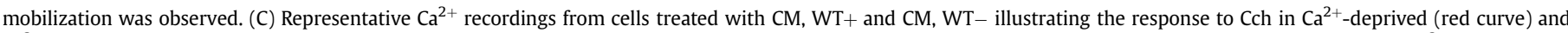

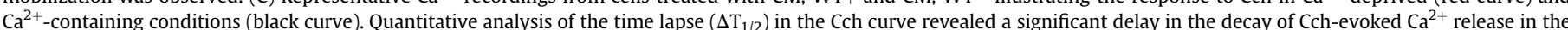

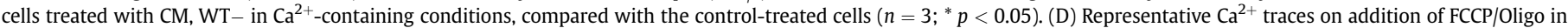

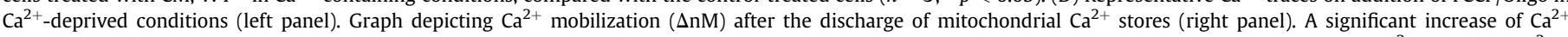

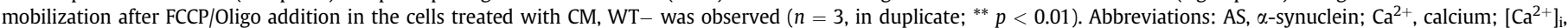

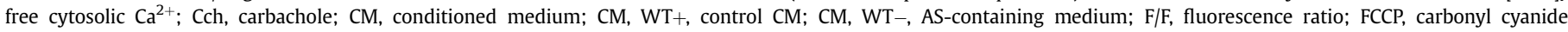
p-trifluromethoxy-phenylhydrazone; Iono, ionomycin; Mon, monensin A; Oligo, oligomycin; Tg, thapsigargin. 
$\mathrm{Ca}^{2+}$ entry compared with control cells (percent of fluorescence ratio $143.3 \pm 3.79$ or $238.7 \pm 17.5$ in cells treated with CM, WT+ and $\mathrm{CM}, \mathrm{WT}-$, respectively), confirming the results obtained with differentiated SH-SY5Y cells.

\subsection{Reduction of cytosolic $\mathrm{Ca}^{2+}$ levels protects from secreted AS-} induced neurotoxicity

To investigate whether extracellular AS mediates its pathogenic actions through increased $\mathrm{Ca}^{2+}$ influx, we used chemical compounds that chelate intracellular or extracellular $\mathrm{Ca}^{2+}$ or prohibit $\mathrm{Ca}^{2+}$ from entering the cell. Six-day differentiated SH-SY5Y cells (Fig. 5A) and 7-day-old rat cortical neurons (Fig. 5D) were incubated for 24 hours at $37^{\circ} \mathrm{C}$ with $\mathrm{CM}, \mathrm{WT}-$ or $\mathrm{CM}, \mathrm{WT}+$, in the presence or absence of nif or cntx, and the intracellular or extracellular $\mathrm{Ca}^{2+}$ chelators, BAPTA-AM (BAPTA) or EGTA, respectively. In both cell types, the presence of extracellular AS led to a decrease in neuronal survival, which was mitigated on addition of either nif, cntx, BAPTA,

\section{A CM: 24 h}

\section{Compound: $24 \mathrm{~h}$}

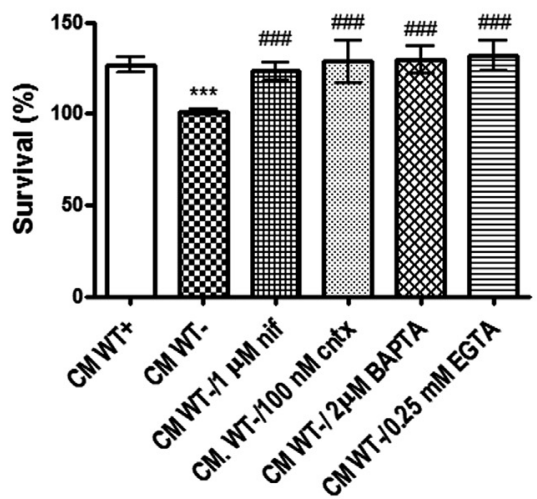

C CM: $24 \mathrm{~h}$

Compound: $8 \mathrm{~h}$

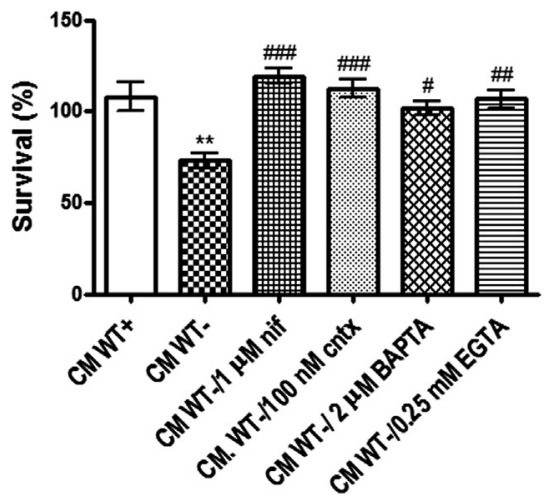

or EGTA (Fig. 5A and D). Drug application had no background toxicity, confirmed in control experiments.

To decipher whether AS-induced $\mathrm{Ca}^{2+}$ deregulation is directly linked to the observed cell death, $\mathrm{Ca}^{2+}$ modulators were added for the first 8 hours together with CM, WT-. Subsequently, the compounds were removed and $\mathrm{CM}$, WT- was added to the cells for additional 8 or 16 hours. We found that the 8 -hour treatment with the chelating compounds and the VOC inhibitors was sufficient to protect differentiated cells from AS-mediated toxicity at all time points (Fig. 5B and C). These results indicate that disturbances in $\mathrm{Ca}^{2+}$ homeostasis are the primary event in AS-triggered neurotoxic cascade.

3.6. Calpain activation is implicated in the extracellular AS-evoked neurotoxic effects

We have previously shown that treatment of neuronal cells with secreted AS results in caspase-3 cleavage (Emmanouilidou et al.,

\section{B CM: $16 \mathrm{~h}$}

\section{Compound: $8 \mathrm{~h}$}

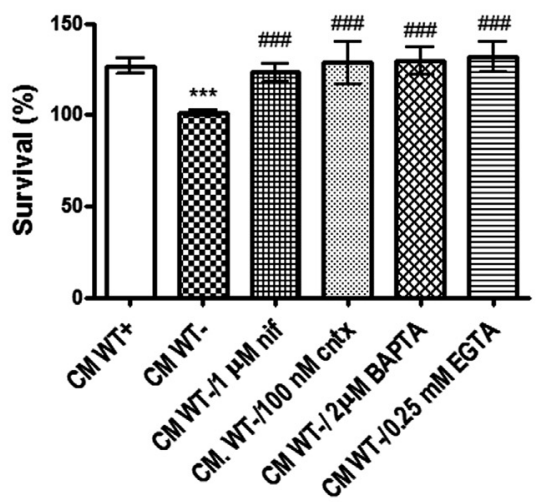

D CM: $24 \mathrm{~h}$

\section{Compound: $24 \mathrm{~h}$}

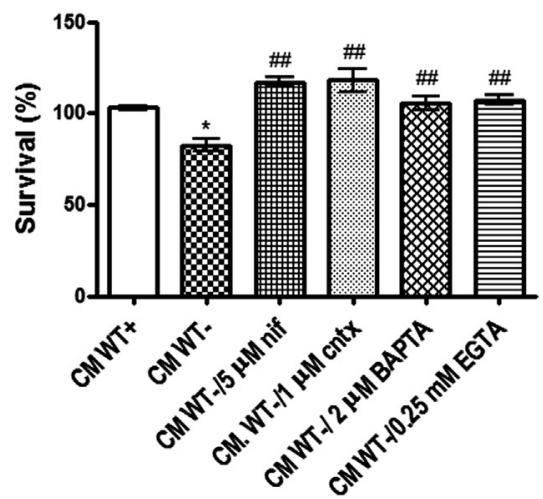

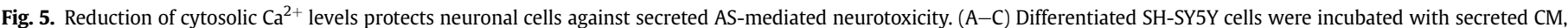

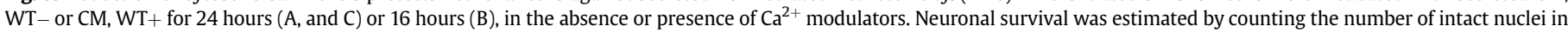

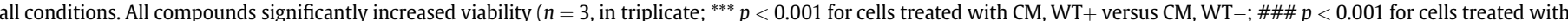

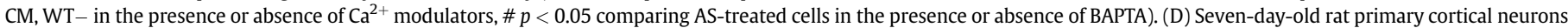

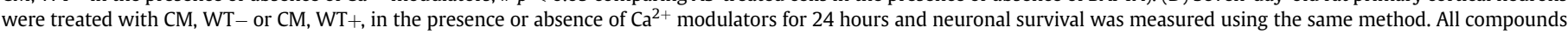

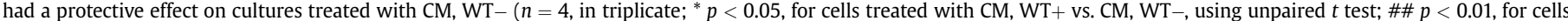

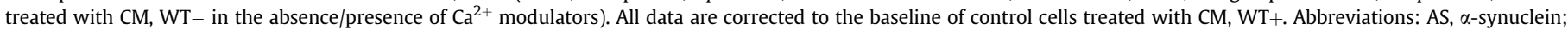
$\mathrm{Ca}^{2+}$, calcium; CM, conditioned medium; CM, WT+, control CM; CM, WT-, AS-containing medium. 
2010). Because calpains have been reported to cleave pro-caspase-3 (Camins et al., 2006) and to be activated in the setting of excess $\mathrm{Ca}^{2+}$, we aimed to examine whether calpains are involved in the secreted AS-induced neurotoxicity. We incubated differentiated SH-SY5Y cells with CM, WT-, CM, WT+, or unconditioned medium (vehicle) for 8, 16 , and 24 hours. Calpain activity was determined in the homogenates of the recipient cells using a calpain-specific fluorogenic substrate. As depicted in Fig. 6A, a statistically significant increase in calpain activity was observed after 24-hour incubation with AS (393.7 $\pm 45.03,499.8$ \pm 17.31 , and $679.7 \pm 30.47$, for the cells treated with vehicle, CM, WT + , and $\mathrm{CM}, \mathrm{WT}-$, respectively). The specificity of the reaction was verified by the addition of the specific $\mathrm{Cl}$, which, as expected, resulted in a significant decrease of calpain activity (Fig. 6A, right panel).

We reasoned that if calpains are indeed activated during the process of AS-induced toxicity, their inactivation should result in an increase of cell survival after AS treatment. To test this hypothesis, we incubated cells with CM, WT - in the presence or absence of the $\mathrm{CI}$, for 24 hours. Addition of $1 \mu \mathrm{M}$ CI greatly improved cell morphology (data not shown) and significantly increased cell viability (Fig. 6B). In a similar fashion to the survival assays with the $\mathrm{Ca}^{2+}$ modulators, we investigated whether calpain activation is a primary event for the observed death. CI was added for 8 hours together with the $\mathrm{CM}, \mathrm{WT}-$. Then, the inhibitor was removed and the cells were incubated for an additional 8 hours or 16 hours with $\mathrm{CM}, \mathrm{WT}-$ alone. Such treatment showed a trend of protection, after 16-hour incubation with CM, WT- $(82.38 \pm 3.57$ and $94.75 \pm 4.39$, for the cells treated CM, WT-, in the absence or presence of CI, respectively) (Fig. 6C), but reached statistical significance only after 24 hours of incubation $(74.25 \pm 4.40$ and $118.8 \pm 3.58$, for the cells treated $\mathrm{CM}, \mathrm{WT}-$, in the absence or presence of $\mathrm{CI}$, respectively) (Fig. 6D).

Similar experiments were performed in rat cortical cultures treated with CM, WT- in the presence or absence of the CI for 24 hours. Such treatment showed that calpain inhibition also improved the survival of primary neurons exposed to AS, however, this effect did not reach statistical significance (Fig. 6E).

\subsection{Interaction of secreted AS with the plasma membrane of recipient cells}

In our previous work, we showed that secreted AS could exert its deleterious effects without frank internalization by differentiated SH-SY5Y cells (Emmanouilidou et al., 2010). Hence we wanted to investigate a potential association between AS and the plasma membrane of recipient cells. To do so, we examined changes in the microfluidic properties of the membrane of AS-treated cells. Cells were treated with CM from induced ASoverexpressing cells, or uninduced cells for 8 hours and incubated with 1-pyrenedodecanoic acid $(2 \mu \mathrm{M})$. 1-Pyrenedodecanoic acid excimers break into monomers in the lipophilic interior of the membrane giving a distinct fluorescence spectrum that is indicative of the microfluidic properties of the membrane (Dafnis et al.,

A

Enzymatic activity assay
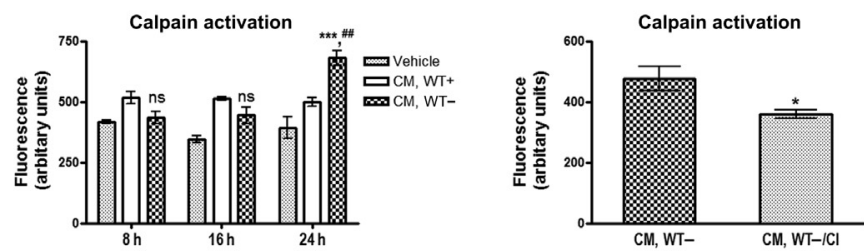

B CM: $24 \mathrm{~h}$

$\mathrm{Cl}: 24 \mathrm{~h}$

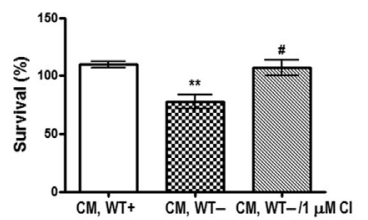

Rat cortical neurons

E cM: $24 \mathrm{~h}$

Cl: $24 \mathrm{~h}$

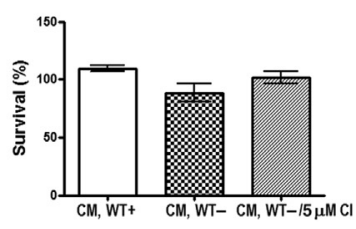

Differentiated SH-SY5Y naive neuroblastoma cells

\section{C}

$\mathrm{Cl}: 8 \mathrm{~h}$

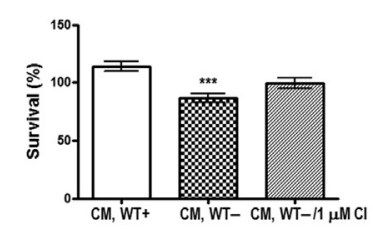

D CM: $24 \mathrm{~h}$

Cl: $8 \mathrm{~h}$

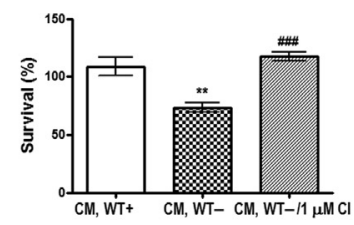

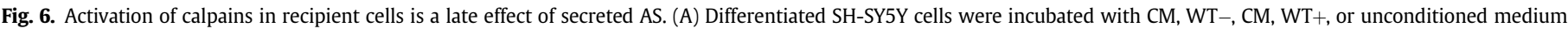

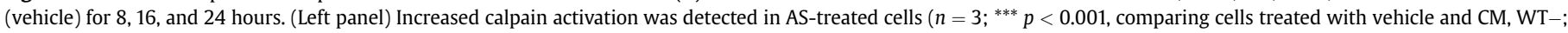

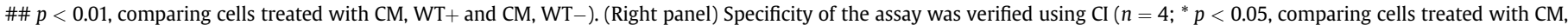

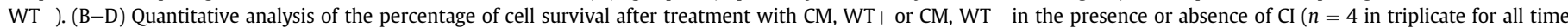

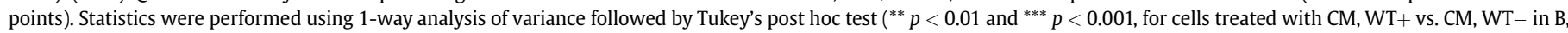

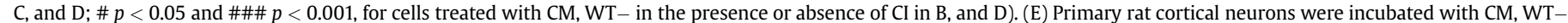

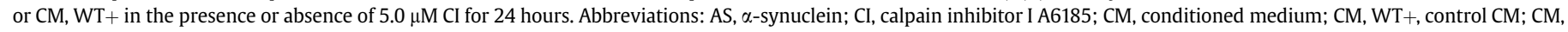
WT-, AS-containing medium. 
2010). The excimer to monomer ratio is an indicator of membrane fluidity with membrane rigidity bringing monomers in close proximity so as to create excised dimers, termed excimers. As shown in Fig. 7A, the excimer to monomer ratio is significantly reduced in AS-treated cells (1.488 \pm 0.071 for CM, WT-, mean \pm SEM; $n=6)$ compared with CM, WT+-treated cells $(1.725 \pm 0.024$ for $\mathrm{CM}, \mathrm{WT}+$, mean $\pm \mathrm{SEM} ; n=6$ ), implying increased membrane fluidity. To exclude the possibility of dox interference in this setup, we collected CM from the Tet-Off parental SH-SY5Y line (2.22) expressing only the transactivator factor, in the absence or presence of dox. In both cases the excimer to monomer ratio was similar to that of the cells treated with the $\mathrm{CM}, \mathrm{WT}+$, suggesting that dox does not interfere with the fluidity assay. The ether phospholipid, miltefosine, known to directly interact and incorporate into the cell membrane, was used as a positive control for increased membrane fluidity (Fig. 7B).

3.8. The observed increase in $\mathrm{Ca}^{2+}$ entry is mostly attributed to the free extracellular-rather than the exosome-associated AS

Because AS is partly secreted via exosomes (Emmanouilidou et al., 2010), we finally sought to investigate the contribution of exosomes in the observed $\mathrm{Ca}^{2+}$ entry. We fractionated CM, WTand $\mathrm{CM}, \mathrm{WT}+$ into exosome-depleted supernatant (S100- and $\mathrm{S} 100+$, respectively) and into exosome-enriched pellet (P100- and P100+, respectively). Full CM and S100 supernatants were concentrated with using 3-kDa cutoff filters. P100 fractions were solubilized in RIPA buffer. Western blot analysis (Fig. 8A) revealed that only a small portion of secreted AS is present in the exosomal fraction, in accordance with our previous results (Emmanouilidou et al., 2010). Alix and flotillin-1 were used as biochemical markers for the exosome-enriched fraction, and BSA was used as loading control for CM and S100.
Exosomes from the CM, WT- medium (P100-) were added in the $\mathrm{S} 100+$ supernatant from the $\mathrm{CM}, \mathrm{WT}+(\mathrm{S} 100+/ \mathrm{P} 100-)$ and vice versa to yield an S100-/P100+ preparation. Cells were incubated with CM, WT-, control medium, or 1 of the previously described preparations (S100+, S100-, S100+/P100-, and S100-/P100+) for 8 hours. The recipient cells were loaded with Fura 2-AM, and ER depletion-induced $\mathrm{Ca}^{2+}$ influx was measured, as described earlier in text (Fig. 8B). Quantification of $\mathrm{Ca}^{2+}$ influx revealed that the observed increase is attributed largely to free extracellular AS (S100-) (percentage of $\mathrm{Ca}^{2+}$ influx, $117.2 \pm 8.79$ and $111.9 \pm 10.87$, for cells treated with CM, WT- and S100-, respectively). The addition of the exosome-associated AS (P100-) in the control S100+ supernatant did not significantly alter the CCE. This suggests that mainly free extracellular AS accounts for secreted AS-facilitated $\mathrm{Ca}^{2+}$ entry. This might be attributed to AS concentration, because only a small portion of secreted AS is packed in exosomes (Fig. 8A). Finally, the addition of $\mathrm{P} 100+$ to the S100 - did not lead to dramatic alterations of the CCE (percentage of $\mathrm{Ca}^{2+}$ influx $111.9 \pm 10.87$ and $101.3 \pm 7.68$, for cells treated with $\mathrm{S} 100-$ and $\mathrm{S} 100-/ \mathrm{P} 100+$, respectively), suggesting that the exosomes per se do not influence CCE.

\section{Discussion}

We have previously shown that cell-produced secreted AS is toxic to neuronal cells. Importantly, this toxicity did not appear to involve internalization of AS by the recipient neurons (Emmanouilidou et al., 2010). The aim of the current study was to investigate whether the effects of secreted AS on the recipient cells involve alterations at the level of the plasma membrane and deregulation of $\mathrm{Ca}^{2+}$ homeostasis.

To capture early events that could be pathologically relevant, the 8-hour treatment with CM containing secreted AS was chosen, because until that time point there are no overt signs of cellular degeneration. According to our results, 8-hour incubation with
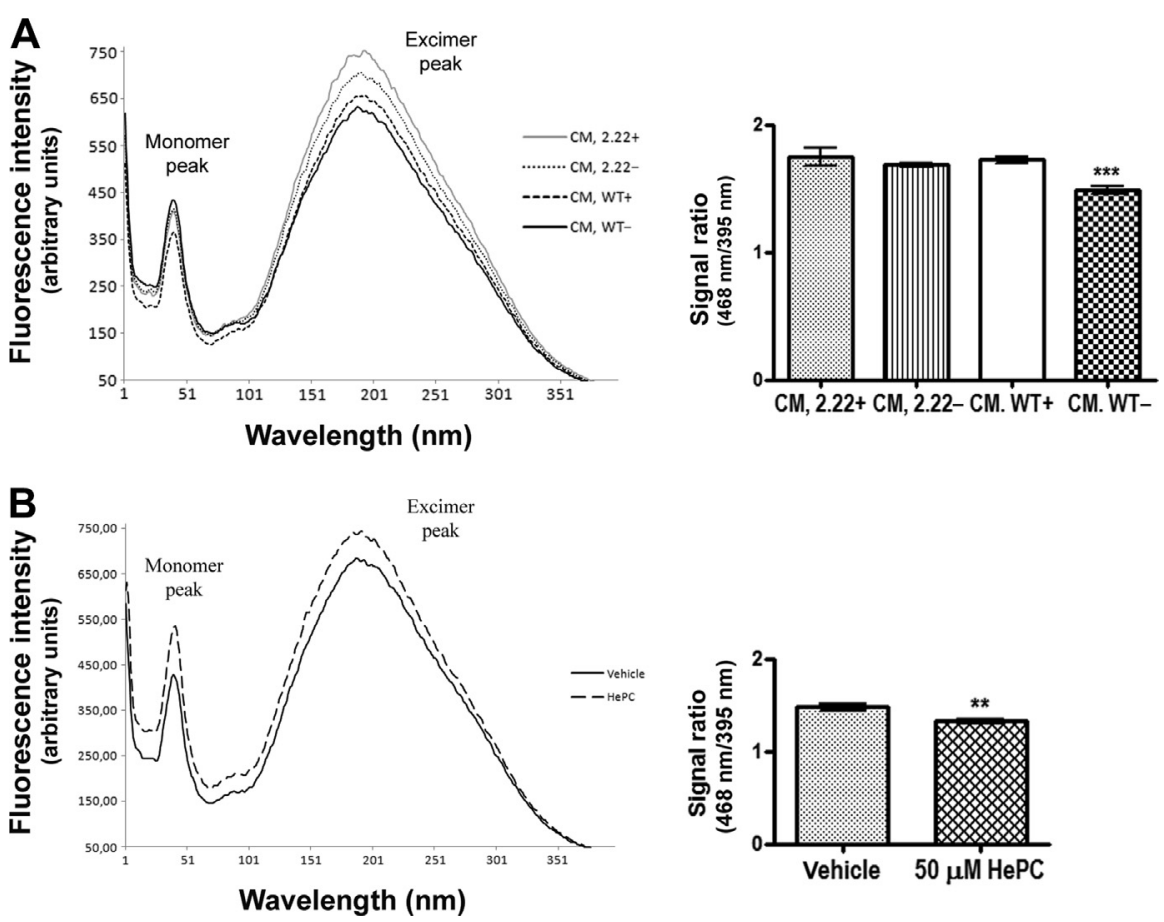

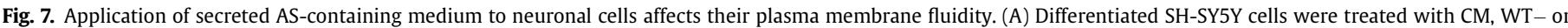

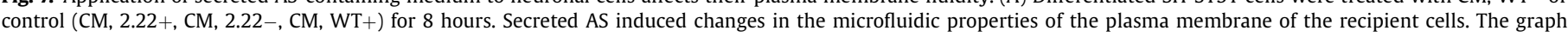

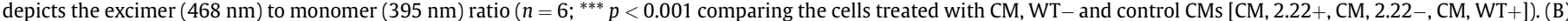

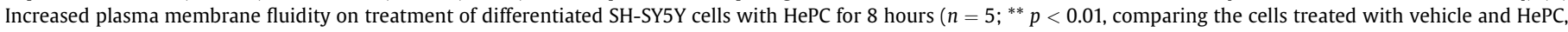
using unpaired $t$ test). Abbreviations: AS, $\alpha$-synuclein; CM, conditioned medium; CM, WT+, control CM; CM, WT-, AS-containing medium; HePC, miltefosine. 
A

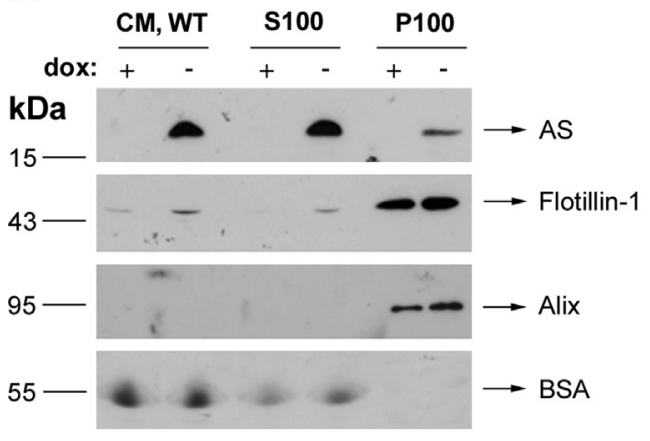

B

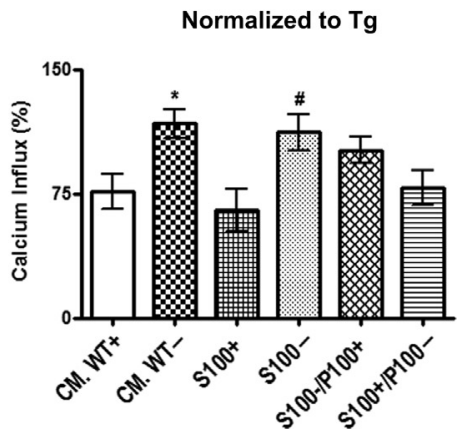

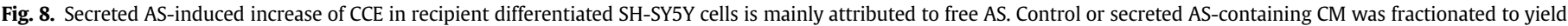

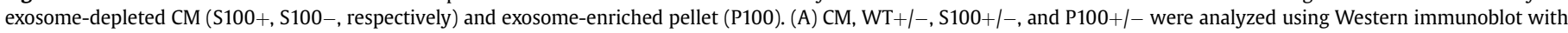

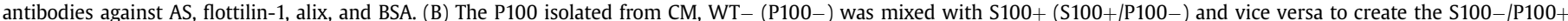

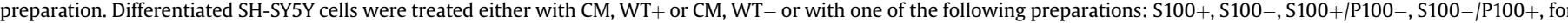

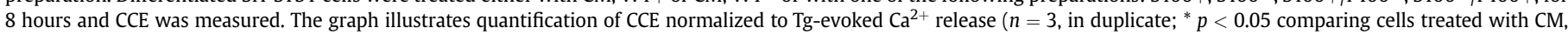

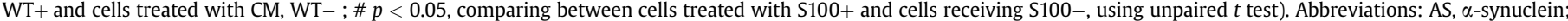

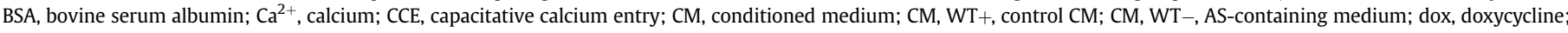
$\mathrm{Tg}$, thapsigargin.

secreted AS was enough to cause $\mathrm{Ca}^{2+}$ perturbations, manifested by a significant increase in depleted ER-evoked $\mathrm{Ca}^{2+}$ entry (CCE), in differentiated SH-SY5Y cells and primary rat cortical neurons. The observed phenomenon greatly relies on the presence of secreted AS, because immunodepletion of the protein from the CM before administration to the cells does not alter CCE. Importantly, the presence of extracellular AS did not have any effect on the CCE of proliferating cells, which we have shown to be less susceptible to AS-conferred toxicity (Emmanouilidou et al., 2010). Additionally, reduction of cytosolic or extracellular $\mathrm{Ca}^{2+}$ levels via the BAPTA and EGTA $\mathrm{Ca}^{2+}$ chelators, respectively, spared recipient neuronal cells from AS-evoked toxicity. These data indicate that deregulation of $\mathrm{Ca}^{2+}$ homeostasis of the recipient cells is responsible, at least in part, for the neurotoxic potential of secreted AS. This raises the possibility that the differential toxic effects of secreted AS in neuronally differentiated versus proliferating cells (Emmanouilidou et al., 2010) might be related to its ability to alter $\mathrm{Ca}^{2+}$ homeostasis in the former, but not in the latter. Although an interplay between extracellular AS and alterations of $\mathrm{Ca}^{2+}$ homeostasis in the recipient cells has been suggested in previous reports, these were largely based on the use of recombinant AS; the current study is, to our knowledge, the first that etiologically links such early $\mathrm{Ca}^{2+}$ perturbations to secreted AS-mediated neurotoxicity.

To further elucidate the neurotoxic pathway triggered by secreted AS, we investigated the participation of plasma membrane $\mathrm{Ca}^{2+}$ channels. Because CCE was found to be increased in the presence of secreted AS, we sought to examine the involvement of SOCs. Although inhibition of SOCs by the specific inhibitor SKF, resulted in a significant reduction of CCE in control and AS-treated differentiated cells, the difference between the 2 groups in the presence of the inhibitor was not completely abolished. Such a finding implies that other plasma membrane channels could contribute to the AS-facilitated $\mathrm{Ca}^{2+}$ entry. Therefore we examined the role of the L- and N-type VOCs, using pharmacological inhibition with nif and cntx, respectively. Such treatment significantly reduces CCE to the control levels in differentiated cells, greatly alleviating AS-induced $\mathrm{Ca}^{2+}$ entry, suggestive of the involvement of VOCs in the observed phenomenon. In accordance with these findings, direct stimulation of VOCs by $\mathrm{KCl}$ depolarization led to a significantly higher $\mathrm{Ca}^{2+}$ influx in AS-treated cells compared with the control cells. Notably, inhibition of either L- or N-type VOCs greatly reduced $\mathrm{Ca}^{2+}$ influx on depolarization in both groups, abolishing the difference between them. These findings prove the proper function of VOCs in the described cellular system and more importantly, verify the role of VOCs in secreted AS-evoked $\mathrm{Ca}^{2+}$ deregulation. Considering that we did not find any changes in the protein levels of VOCs (data not shown) on exposure of the cells to secreted AS, the described $\mathrm{Ca}^{2+}$ increase cannot be attributed to an upregulation of the expression levels of these channels. Instead, we saw that the presence of extracellular AS increased membrane fluidity of the recipient neuronal cells, potentially allowing the redistribution and clustering of plasma membrane receptors (including $\mathrm{Ca}^{2+}$-dependent channels), which in turn might facilitate their activation and sensitivity to $\mathrm{Ca}^{2+}$. Nonetheless, we cannot exclude the possibility of a direct interaction between secreted AS and the plasma membrane receptors, resulting in alteration of their function.

Because recombinant AS species have been shown to interact with artificial and biological membranes creating annular pores (Danzer et al., 2007; Tsigelny et al., 2012), we investigated the effect of AS on an Iono-evoked response. If the interaction of AS with the plasma membrane caused the formation of pores, the Iono-evoked response would result in a profound $\mathrm{Ca}^{2+}$ rise, in $\mathrm{Ca}^{2+}$-containing conditions. Nevertheless, we found no significant difference in $\left[\mathrm{Ca}^{2+}\right]_{\mathrm{i}}$ between AS-treated and control cells suggesting that the likelihood of pore formation (at least at this early time point) is unlikely. However, we cannot exclude the possibility that such pores are formed at later time points (Schmidt et al., 2012; Tsigelny et al., 2012). The notion that secreted AS perturbs the normal function of the plasma membrane of the recipient cells, by facilitating increased $\mathrm{Ca}^{2+}$ influx, is further supported by the significantly slow buffering rate of the Cch-evoked $\mathrm{Ca}^{2+}$ rise in $\mathrm{Ca}^{2+}$-containing compared with $\mathrm{Ca}^{2+}$-deprived conditions, exhibited by AS-treated cells compared with the control cells.

Despite the profound increase in the observed $\mathrm{Ca}^{2+}$ entry, no significant changes in the steady-state levels of $\left[\mathrm{Ca}^{2+}\right]_{i}$ were measured in AS-treated cells compared with control cells. Sequential $\mathrm{Ca}^{2+}$ release from the ER and the acidic stores did not reveal any striking differences in both $\mathrm{Ca}^{2+}$-depleted and $\mathrm{Ca}^{2+}$ containing conditions, excluding the possibility of alterations in $\mathrm{Ca}^{2+}$ mobilization. Direct discharge of the mitochondrial $\mathrm{Ca}^{2+}$ content using simultaneous administration of the mitochondrial uncoupler FCCP and Oligo, showed significantly increased $\mathrm{Ca}^{2+}$ sequestration in AS-treated cells, suggestive of mitochondrial $\mathrm{Ca}^{2+}$ 
overload. It is possible that such overload might lead to mitochondrial dysfunction, thus linking extracellular AS and $\mathrm{Ca}^{2+}$ overload to the mitochondrial theory of PD pathogenesis (Benner et al., 2004; Cali et al., 2012; Vekrellis and Stefanis, 2012; Zhou et al., 2004).

Uncontrolled $\mathrm{Ca}^{2+}$ entry can result in the activation of calpains, a specific type of cystein- protease that responds to $\mathrm{Ca}^{2+}$ signals (Medeiros et al., 2012). An increasing body of evidence gradually cements the notion that abnormal activation of calpains is 1 of the major culprits in a wide spectrum of brain disorders (Camins et al., 2006). However, the precise mechanism via which calpains regulate cell death pathways remains to be deciphered. Calpain activity was found to be increased in the protein preparations extracted from cells treated with AS for 24 hours, suggesting that calpain activation is a secondary event that follows $\mathrm{Ca}^{2+}$ deregulation. Considering that calpains can mediate caspase cleavage and activation (Camins et al., 2006), and that secreted AS-induced toxicity results in caspase-3 cleavage (Emmanouilidou et al., 2010), these data suggest a potential cross-talk between calpains and caspases. In our study, pharmacological inhibition of calpains protected neuronal cells from AS-induced death, further reinforcing the involvement of calpains in the described neurodegenerative process. However, this effect was more profound in differentiated SH-SY5Y cells than in rat cortical neurons, possibly because higher doses and more effective calpain inhibition were not achieved in the latter case, because of pharmacological toxicity observed with higher doses. In any case, the incomplete effects of calpain inhibition in rat cortical neurons suggest that other death pathways could contribute to the observed neurotoxicity.

It is important to note that an 8-hour treatment with chelating compounds (BAPTA, EGTA) and VOC inhibitors was enough to protect differentiated SH-SY5Y cells from 16 or 24 hours of total incubation with $\mathrm{CM}, \mathrm{WT}-$, thus placing $\mathrm{Ca}^{2+}$ deregulation at the beginning of the AS-triggered neurotoxic cascade. On the contrary, similar administration of $\mathrm{CI}$ started to be protective after the 16hour incubation with CM, WT- and showed maximum protection after the 24-hour treatment. Taking into account the enzymatic activity data, which shows calpain activation after 16 hours of exposure to secreted AS, the above finding implies that calpains might be activated at 16 hours (albeit at low, nondetectable levels), but this activation was significant only at 24 hours. Therefore, it seems that calpain activation is 1 of the late events of the secreted AS-evoked neurotoxic cascade, downstream $\mathrm{Ca}^{2+}$ deregulation. However, further investigation is required to elucidate the precise involvement of calpains in this phenomenon.

We have shown that AS species can be delivered to the extracellular space, at least partly, via their association with exosomes. Measurements of CCE in recipient cells treated with free extracellular AS or exosome-associated AS preparations, revealed that free extracellular AS was more potent in inducing increased $\mathrm{Ca}^{2+}$ entry, compared with the exosome-associated protein. This difference in $\mathrm{Ca}^{2+}$ response might be because of the conformational changes that AS undergoes on packaging into exosomes which might affect its biochemical properties. In addition, considering that only a minor fraction of secreted AS is associated with exosomes (Danzer et al., 2012), this result might also reflect concentration differences.

Concluding, our findings indicate that secreted AS has neurotoxic effects, at least in part, through engagement of the $\mathrm{Ca}^{2+}$ homeostatic machinery. In this context, handling of $\mathrm{Ca}^{2+}$ signaling cascades might represent a potential therapeutic target for PD and related synucleinopathies by alleviating secreted AS-conferred neurotoxicity. Furthermore, our study provides a number of important novel mechanistic insights regarding the effect of secreted AS on neuronal cells. Initial effects leading to increased $\mathrm{Ca}^{2+}$ influx are linked to altered membrane fluidity, likely causing clustering or oversensitization of VOCs, whereas pore formation does not appear to play a role at these early time points. In the further cascade of events, calpain activation and, possibly, mitochondrial $\mathrm{Ca}^{2+}$ overload, are important factors leading to neurotoxicity.

\section{Disclosure statement}

There is no actual or potential conflicts of interest related to the work presented in this manuscript.

All animals were handled according to the ethical standards of BRFAA under protocols approved by the Animal Care and Use Committee of the Institution and in accordance with the European Convention 123/Council of Europe and Directive 86/609/EEC.

\section{Acknowledgements}

The authors thank the BRFFA biological imaging facility for assistance with $\mathrm{Ca}^{2+}$ imaging experiments, and Dr Chroni for her technical advice on the setup of the membrane fluidity assay. This research was cofinanced by the European Union (European Social Fund - ESF) and Greek national funds of the National Strategic Reference Framework (NSRF) - Research Funding Program: Heracleitus II. Additional funding for this project was provided by MEFOPA, FP7.

\section{References}

Adamczyk, A., Strosznajder, J.B., 2006. Alpha-synuclein potentiates $\mathrm{Ca}^{2+}$ influx through voltage-dependent $\mathrm{Ca}^{2+}$ channels. Neuroreport 17, 1883-1886.

Banoczi, Z., Alexa, A., Farkas, A., Friedrich, P., Hudecz, F., 2008. Novel cell-penetrating calpain substrate. Bioconjug. Chem. 19, 1375-1381.

Benner, E.J., Mosley, R.L., Destache, C.J., Lewis, T.B., Jackson-Lewis, V., Gorantla, S. Nemachek, C., Green, S.R., Przedborski, S., Gendelman, H.E., 2004. Therapeutic immunization protects dopaminergic neurons in a mouse model of Parkinson's disease. Proc. Natl. Acad. Sci. U.S.A. 101, 9435-9440.

Berridge, M.J., Bootman, M.D., Roderick, H.L., 2003. Calcium signalling: dynamics, homeostasis and remodelling. Nat. Rev. Mol. Cell Biol. 4, 517-529.

Cali, T., Ottolini, D., Negro, A., Brini, M., 2012. $\alpha$-Synuclein controls mitochondrial calcium homeostasis by enhancing endoplasmic reticulum-mitochondria interactions. J. Biol. Chem. 287, 17914-17929.

Camins, A., Verdaguer, E., Folch, J., Pallas, M., 2006. Involvement of calpain activation in neurodegenerative processes. CNS Drug Rev. 12, 135-148.

Chivet, M., Hemming, F., Pernet-Gallay, K., Fraboulet, S., Sadoul, R., 2012. Emerging role of neuronal exosomes in the central nervous system. Front. Physiol. 3, 145

Churchill, G.C., Okada, Y., Thomas, J.M., Genazzani, A.A., Patel, S., Galione, A., 2002 NAADP mobilizes $\mathrm{Ca}(2+)$ from reserve granules, lysosome-related organelles, in sea urchin eggs. Cell 111, 703-708.

Dafnis, I., Stratikos, E., Tzinia, A., Tsilibary, E.C., Zannis, V.I., Chroni, A., 2010. An apolipoprotein E4 fragment can promote intracellular accumulation of amyloid peptide beta 42 . J. Neurochem. 115, 873-884.

Danzer, K.M., Haasen, D., Karow, A.R., Moussaud, S., Habeck, M., Giese, A. Kretzschmar, H., Hengerer, B., Kostka, M., 2007. Different species of alphasynuclein oligomers induce calcium influx and seeding. J. Neurosci. 27, 9220-9232.

Danzer, K.M., Kranich, L.R., Ruf, W.P., Cagsal-Getkin, O., Winslow, A.R., Zhu, L. Vanderburg, C.R., McLean, P.J., 2012. Exosomal cell-to-cell transmission of alpha synuclein oligomers. Mol. Neurodegener. 7, 42.

Dauer, W., Przedborski, S., 2003. Parkinson's disease: mechanisms and models. Neuron 39, 889-909.

de Brito, O.M., Scorrano, L., 2008. Mitofusin 2 tethers endoplasmic reticulum to mitochondria. Nature 456, 605-610.

Demuro, A., Parker, I., Stutzmann, G.E., 2010. Calcium signaling and amyloid toxicity in Alzheimer disease. J. Biol. Chem. 285, 12463-12468.

Emmanouilidou, E., Melachroinou, K., Roumeliotis, T., Garbis, S.D., Ntzouni, M. Margaritis, L.H., Stefanis, L., Vekrellis, K., 2010. Cell-produced alpha-synuclein is secreted in a calcium-dependent manner by exosomes and impacts neuronal survival. J. Neurosci. 30, 6838-6851.

Farinelli, S.E., Greene, L.A., Friedman, W.J., 1998. Neuroprotective actions of dipyridamole on cultured CNS neurons. J. Neurosci. 18, 5112-5123.

Furukawa, K., Matsuzaki-Kobayashi, M., Hasegawa, T., Kikuchi, A., Sugeno, N., Itoyama, Y., Wang, Y., Yao, P.J., Bushlin, I., Takeda, A., 2006. Plasma membrane ion permeability induced by mutant alpha-synuclein contributes to the degeneration of neural cells. J. Neurochem. 97, 1071-1077. 
Galla, H.J., Luisetti, J., 1980. Lateral and transversal diffusion and phase transitions in erythrocyte membranes. An excimer fluorescence study. Biochim. Biophys. Acta $596,108-117$.

Gasser, T., 2009. Molecular pathogenesis of Parkinson disease: insights from genetic studies. Expert Rev. Mol. Med. 11, e22.

Greer, P.L., Greenberg, M.E., 2008. From synapse to nucleus: calcium-dependent gene transcription in the control of synapse development and function. Neuron 59, 846-860.

Hashimoto, M., Hossain, S., Masumura, S., 1999. Effect of aging on plasma membrane fluidity of rat aortic endothelial cells. Exp. Gerontol. 34, 687-698.

Hettiarachchi, N.T., Parker, A., Dallas, M.L., Pennington, K., Hung, C.C., Pearson, H.A., Boyle, J.P., Robinson, P., Peers, C., 2009. $\alpha$-Synuclein modulation of Ca2+ signaling in human neuroblastoma (SH-SY5Y) cells. J. Neurochem. 111, 1192-1201.

Kang, S., Cooper, G., Dunne, S.F., Dusel, B., Luan, C.H., Surmeier, D.J., Silverman, R.B., 2012. CaV1.3-selective L-type calcium channel antagonists as potential new therapeutics for Parkinson's disease. Nat. Commun. 3, 1146.

Kordower, J.H., Chu, Y., Hauser, R.A., Olanow, C.W., Freeman, T.B., 2008. Transplanted dopaminergic neurons develop PD pathologic changes: a second case report. Mov. Disord. 23, 2303-2306.

Lamarca, V., Scorrano, L., 2009. When separation means death: killing through the mitochondria, but starting from the endoplasmic reticulum. EMBO J. 28, 1681-1683.

Li, J.Y., Englund, E., Holton, J.L., Soulet, D., Hagell, P., Lees, A.J., Lashley, T., Quinn, N.P., Rehncrona, S., Bjorklund, A., Widner, H., Revesz, T., Lindvall, O., Brundin, P., 2008. Lewy bodies in grafted neurons in subjects with Parkinson's disease suggest host-to-graft disease propagation. Nat. Med. 14, 501-503.

Martin, Z.S., Neugebauer, V., Dineley, K.T., Kayed, R., Zhang, W., Reese, L.C., Taglialatela, G., 2012. $\alpha$-Synuclein oligomers oppose long-term potentiation and impair memory through a calcineurin-dependent mechanism: relevance to human synucleopathic diseases. J. Neurochem. 120, 440-452.

Medeiros, R., Kitazawa, M., Chabrier, M.A., Cheng, D., Baglietto-Vargas, D., Kling, A., Moeller, A., Green, K.N., LaFerla, F.M., 2012. Calpain inhibitor A-705253 mitigates Alzheimer's disease-like pathology and cognitive decline in aged 3xTgAD mice. Am. J. Pathol. 181, 616-625.

Nalls, M.A., Plagnol, V., Hernandez, D.G., Sharma, M., Sheerin, U.M., Saad, M., SimonSanchez, J., Schulte, C., Lesage, S., Sveinbjornsdottir, S., Stefansson, K., Martinez, M. Hardy, J. Heutink, P., Brice, A, Gasser, T., Singleton, A.B. Wood, N.W., 2011. Imputation of sequence variants for identification of genetic risks for Parkinson's disease: a meta-analysis of genome-wide association studies. Lancet 377, 641-649.

Papazafiri, P., Bossi, M., Meldolesi, J., 1994. Expression of muscle calsequestrin in epithelial HeLa cells: distribution and functional role. Biochim. Biophys. Acta 1223, 333-340.
Patel, S., Docampo, R., 2010. Acidic calcium stores open for business: expanding the potential for intracellular Ca2+ signaling. Trends Cell Biol. 20, 277-286.

Schmidt, F., Levin, J., Kamp, F., Kretzschmar, H., Giese, A., Botzel, K., 2012. Singlechannel electrophysiology reveals a distinct and uniform pore complex formed by alpha-synuclein oligomers in lipid membranes. PloS One 7, e42545.

Smaili, S.S., Russell, J.T., 1999. Permeability transition pore regulates both mitochondrial membrane potential and agonist-evoked $\mathrm{Ca} 2+$ signals in oligodendrocyte progenitors. Cell Calcium 26, 121-130.

Spillantini, M.G., Schmidt, M.L., Lee, V.M., Trojanowski, J.Q., Jakes, R., Goedert, M. 1997. Alpha-synuclein in Lewy bodies. Nature 388, 839-840.

Stefanis, L., Park, D.S., Friedman, W.J., Greene, L.A., 1999. Caspase-dependent and -independent death of camptothecin-treated embryonic cortical neurons. J. Neurosci. 19, 6235-6247.

Surmeier, D.J., Guzman, J.N., Sanchez-Padilla, J., 2010. Calcium, cellular aging, and selective neuronal vulnerability in Parkinson's disease. Cell Calcium 47, 175-182.

Thery, C., Amigorena, S., Raposo, G., Clayton, A., 2006. Isolation and characterization of exosomes from cell culture supernatants and biological fluids. Curr. Protoc. Cell Biol. Chapter 3, Unit 3.22.

Tsigelny, I.F., Sharikov, Y., Wrasidlo, W., Gonzalez, T., Desplats, P.A., Crews, L., Spencer, B., Masliah, E., 2012. Role of alpha-synuclein penetration into the membrane in the mechanisms of oligomer pore formation. FEBS J. 279, 1000-1013.

Vekrellis, K., Stefanis, L., 2012. Targeting intracellular and extracellular alphasynuclein as a therapeutic strategy in Parkinson's disease and other synucleinopathies. Expert Opin. Ther. Targets 16, 421-432.

Vekrellis, K., Xilouri, M., Emmanouilidou, E., Rideout, H.J., Stefanis, L., 2011. Pathological roles of alpha-synuclein in neurological disorders. Lancet Neurol. 10, 1015-1025.

Vekrellis, K., Xilouri, M., Emmanouilidou, E., Stefanis, L., 2009. Inducible overexpression of wild type alpha-synuclein in human neuronal cells leads to caspase-dependent non-apoptotic death. J. Neurochem. 109, 1348-1362.

Vogiatzi, T., Xilouri, M., Vekrellis, K., Stefanis, L., 2008. Wild type alpha-synuclein is degraded by chaperone-mediated autophagy and macroautophagy in neuronal cells. J. Biol. Chem. 283, 23542-23556.

Yamasaki, M., Masgrau, R., Morgan, A.J., Churchill, G.C., Patel, S., Ashcroft, S.J. Galione, A., 2004. Organelle selection determines agonist-specific Ca2+ signals in pancreatic acinar and beta cells. J. Biol. Chem. 279, 7234-7240.

Zhou, C., Emadi, S., Sierks, M.R., Messer, A., 2004. A human single-chain Fv intrabody blocks aberrant cellular effects of overexpressed alpha-synuclein. Mol. Ther. 10 1023-1031.

Zundorf, G., Reiser, G., 2011. Calcium dysregulation and homeostasis of neural calcium in the molecular mechanisms of neurodegenerative diseases provide multiple targets for neuroprotection. Antiox. Redox Signal 14 1275-1288. 